TITLE:

\title{
Neural representations of the committed romantic partner in the nucleus accumbens
}

$\operatorname{AUTHOR}(\mathrm{S})$ :

Ueda, Ryuhei; Abe, Nobuhito

CITATION:

Ueda, Ryuhei ...[et al]. Neural representations of the committed romantic partner in the nucleus accumbens. Psychological Science 2021, 32(12): 1884-1895

ISSUE DATE:

2021-12

URL:

http://hdl.handle.net/2433/267547

RIGHT:

Ryuhei Ueda; Nobuhito Abe, Neural representations of the committed romantic partner in the nucleus accumbens, Psychological Science (Volume: 32 issue: 12) pp. 1884-1895. Copyright @ The Author(s) 2021. DOI:

https://doi.org/10.1177/09567976211021854.; This is not the published version. Please cite only the published version. この論文は出版社版でありません。引用の際には出版社版をご確認ご利用ください。 
1 Title: Neural representations of the committed romantic partner in the

16 Ryuhei Ueda

17 Kokoro Research Center, Kyoto University

18 E-mail: ueda.ryuhei.24@gmail.com

\section{nucleus accumbens}

Running title: Neural representations of the romantic partner

$$
\text { Ryuhei Ueda }{ }^{1,2} \text { and Nobuhito Abe }{ }^{1}
$$

${ }^{1}$ Kokoro Research Center, Kyoto University, 46 Shimoadachi-cho, Yoshida Sakyo-ku, Kyoto 606-8501, Japan

${ }^{2}$ Center for Information and Neural Networks (CiNet), National Institute of Information and Communications Technology (NICT), 1-4 Yamadaoka, Suita City, Osaka 565-0871, Japan

19 


\section{Abstract}

2 Having an intimate romantic relationship is an important aspect of life. Dopamine-rich

3 reward regions, including the nucleus accumbens (NAcc), have been identified as neural

4 correlates for both emotional bonding with the partner and interest in unfamiliar attractive

5 nonpartners. Here, we aimed to disentangle the overlapping functions of the NAcc using

6 multivoxel pattern analysis (MVPA), which can decode the cognitive processes encoded

7 in particular neural activity. Forty-six romantically involved males performed the social

8 incentive delay task during fMRI scanning, in which a successful response resulted in the

9 presentation of a dynamic and positive facial expression from their partner and unfamiliar

10 females. MVPA revealed that the spatial patterns of NAcc activity could successfully

11 discriminate between partner and unfamiliar females while anticipating the target

12 presentation. We speculate that neural activity patterns within the NAcc represent the

13 committed partner, which might be a key neural mechanism for single-minded romantic

14 relationships.

15

16 Keywords: fMRI, reward, romantic love, social cognition, value 


\section{Statement of Relevance}

2 Having an intimate romantic relationship with a significant other is an important aspect

3 of life for most people. Brain imaging studies have indicated that dopamine-rich regions

4 of our brain underlie the euphoria of love. However, we know little about whether and

5 how a romantically involved individual's brain encodes a significant other differently

6 from other opposite-sex, attractive individuals. Here, we provide evidence for distinct

7 spatial patterns of activity in the brain's center of pleasure and addiction, the nucleus

8 accumbens, for committed partners and unfamiliar nonpartners. The unique neural

9 representations of a committed partner might be associated with single-minded romantic

10 relationships. 
1

2 Romantic love is observed in nearly all societies (Jankowiak and Fischer 1992).

3 Emotional bonding with a partner usually involves intrusive thinking about the partner

\section{Introduction}

(Fisher 2004) and positively affects physical and mental health (Holmes and Rahe 1967;

House et al. 1988; Uchino et al. 1996; Diener et al. 1999; Kiecolt-Glaser and Newton 2001; Furman 2002). Romantically involved individuals tend to exhibit a more positive evaluation of their partner's attractiveness than others do (Murray et al. 1996; Murray and Holmes 1997; Barelds-Dijkstra and Barelds 2008; Barelds et al. 2011). These individuals also exhibit a more significant devaluation and less attentive adhesion toward alternative partners, which could contribute to relationship maintenance (Johnson and Rusbult 1989; Simpson et al. 1990; Miller 1997; Maner et al. 2008, 2009).

Early studies using functional magnetic resonance imaging (fMRI) aimed to reveal how emotional bonding with a committed partner is established and maintained. Those studies reported greater neural responses to their romantic partner in dopaminerich reward regions, including the ventral tegmental area, caudate nucleus, and nucleus accumbens (NAcc) (e.g., Bartels and Zeki 2000; Aron et al. 2005; Fisher et al. 2010; Acevedo et al. 2012). These mechanisms are believed to be shared with other animals, including prairie voles, which exhibit a selective preference for the partner in long-term paired relationships (for reviews, Young and Wang 2004; Walum and Young 2018). Recent fMRI studies have found the reward circuitry to be involved in love, regardless of relationship length (e.g., >10 years in Acevedo et al. 2012), culture (Xu et al. 2011), or sexual orientation (Zeki and Romaya 2010).

However, it is still unknown whether this circuitry encodes unique neural representations related to the partner. Greater responses in the reward circuitry to the 
1 opposite-sex partner may simply indicate a preference for attractive opposite-sex

2 individuals (e.g., Aharon et al. 2001; Kim et al. 2007; Bzdok et al. 2011; Mende-Siedlecki

3 et al. 2013) regardless of the relationship. Disentangling the reward circuitry's 4 overlapping functions could clarify the cognitive mechanisms that underlie exclusive and

5 long-term relationship commitment.

We used multivoxel pattern analysis (MVPA), which uses a machine learning technique to decode the mental states, or the cognitive processes elicited by different

8 stimuli from the spatial patterns of activity in a given brain region (Haxby et al. 2014;

9 Cohen et al. 2017). MVPA exhibits higher sensitivity than the traditional univariate fMRI approach and allows better interpretation of overlapping functional activations in a targeted region (Norman et al. 2006; Peelen and Downing 2007). Among the rewardrelated regions, we focused on the NAcc as potentially containing a unique representation of the committed partner for the following two reasons. First, as described above, the NAcc has been believed to play a crucial role in establishing emotional bonding with a long-term partner (Young and Wang 2004; Fisher et al. 2010; Acevedo et al. 2012; Walum and Young 2018). Second, several studies have demonstrated that oxytocin treatment promotes avoidance behaviors for alternative partners and selectively enhances the perceived attractiveness of the committed partner, paralleled by an increased NAcc response (Scheele et al. 2012, 2013, 2016; Kreuder et al. 2017). Based on these observations, the NAcc likely differentially encodes representations of the committed partner relative to other opposite-sex individuals.

To effectively measure NAcc activity, we employed a variant of the social reward incentive delay (SID) task (Spreckelmeyer et al. 2009), an adaptation of the monetary

24 incentive delay task (Knutson et al. 2000), which requires participants to quickly and 
1 accurately respond to the presentation of a target following a cue. The SID task includes

2 a brief delay before striving to gain social approval from different persons to maximize

3 the motivational aspects of reward processing, allowing measurement of neural activity

4 that represents reward anticipation in the absence of deliberate evaluation. Here, we

5 expected to observe distinct neural representations in the NAcc between the committed 6 partner and other opposite-sex individuals. 
1 Materials and Methods

$2 \quad$ Participants

3 The participants in this study were 46 right-handed males with no history of neurological

4 or psychiatric disease. The optimal sample size was determined based on a G-Power

5 analysis (Version 3.1.9.4; Faul et al. 2007, 2009). A sample size of 36 participants was

6 required to reach a power of 0.9 , with a medium effect size of $d=0.5$ for the one-sample

7 t-test (one-tailed) to test decoding accuracy against chance level (Means: Difference from

8 constant, one sample case) and an $\alpha$ level of 0.05. Assuming an exclusion rate of

9 approximately $20 \%$, a final sample size of 46 was determined to be required. Because males generally express a stronger desire for romantic relationships with more individuals (Buss and Schmitt 1993; Wiederman 1997), we chose only heterosexual males for the present investigation to reduce confounding factors and render the studied phenomena clearer. All volunteers were between 20 and 29 years old and were in a committed romantic relationship at the time of the experiment. The female partners of the participants also participated in this study through a video recording, in which we collected their pictures and movie clips to be presented in the fMRI task (see Section 1 in Supplemental Material). We excluded eight volunteers from the analysis for the following reasons: four exhibited excessive head motion during fMRI scanning (repetitive movements larger than $2 \mathrm{~mm}$ within a session), one had neurological abnormalities that were identified during scanning, and three self-identified as gay. Thus, the present results were based on the remaining 38 participants (mean age $=21.9$ years; range $=20-27$ years). No participants were in a marital relationship. The mean length of relationship with the current partner was 18.3 months $(\mathrm{SD}=13.3$ months; median $=15.5$ months; range $=2-66$ months). We did not assess whether the participant was living with 
1 his partner. The mean number of partners, including past partners, was $2.7(\mathrm{SD}=1.3$,

2 median $=3$, range $=1-7$ ). After receiving a detailed description of the study, all

3 participants provided written informed consent that conformed with the guidelines

4 approved by the Ethics Committee of Kyoto University.

$6 \underline{\text { Tasks }}$

SID task. The participants were engaged in the SID task during fMRI scanning,

8 which assesses the neural responses that underlie the anticipation of positive feedback

9 from a cued person (Spreckelmeyer et al. 2009; Rademacher et al. 2010; Kohls et al. 2013). Figure 1 presents a schematic diagram for the SID task. In the present study, the SID task had four conditions: partner female, attractive female, unattractive female, and control. Similar to a previous study (Kohls et al. 2013), we prepared facial pictures and short movie clips for each person presented in the SID task as stimuli (see Section 1 in Supplemental Material). The stimuli presented in the partner condition were unique to each participant (i.e., the participant's current partner's facial picture and movie clips). The stimuli for the attractive and unattractive conditions were fixed for all participants. For the stimuli presented in the control condition, we created mosaicked pictures and movie clips generated from stimuli presented in the other three experimental conditions. The SID task is a simple speeded response task, where pressing a button during the brief presentation of the target stimulus was considered a successful response and resulted in observing a movie clip depicting positive feedback from the cued person. Notably, the participants were informed of the type of trial at the beginning of the trial; in this way, the extent to which the participants were motivated to obtain positive

24 feedback from the viewed person could be assessed based on both reaction time and 
1 neural response during the anticipation of the target presentation. Because anticipatory

2 delay involves no explicit evaluation, observing this allows us to minimize possible

3 confounding effects, such as concerns about the social desirability of demonstrating a

4 preference for a potential alternative partner (Scott 2000).

The task consisted of five sessions, where each session lasted approximately 7

$6 \mathrm{~min}$ and $40 \mathrm{~s}$. Each session consisted of four conditions (partner, attractive, unattractive,

7 and control) with ten trials for each condition. A total of 40 trials were presented in a

8 pseudorandom order. At the beginning of each trial, the participants viewed a neutral-

9 expression facial picture for $1000 \mathrm{~ms}$, which indicated the trial type. For example, in the partner condition, a picture of the partner with a neutral expression appeared on the screen as a cue. Following the cue presentation, the participants were presented with an object that indicated the target's presentation within a variable interval (anticipatory delay phase, 2000-2500 ms). Upon the appearance of a white target square that appeared for a variable length of time (150-450 ms), the participants responded with a button press. They were instructed to press the button with their right forefinger as rapidly as possible in response to the appearance of the target square in all conditions. In the subsequent outcome phase, the target hits (i.e., responses that occur during the presentation of the target stimulus) resulted in the presentation of a short movie clip of the cued person for $1500 \mathrm{~ms}$, who showed happy facial expressions and a positive gesture (Hit). There were ten positive movie clips for each person (see Section 1 in Supplemental Material), and they appeared on the screen in a pseudorandom order in each session to encourage participants to maintain engagement with the task. Error responses (i.e., responses that occur in the absence of the target stimulus) resulted in the presentation of a short movie clip of the cued person with a neutral facial expression without any gestures for $1500 \mathrm{~ms}$ (Miss). 
1 Unlike the hit trials, a single movie clip was presented in the miss trials for each condition.

2 A fixation was presented for a variable intertrial interval (4000-8000 ms) following each

3 trial. In trials for the control condition, a mosaicked picture was presented as a cue, and

4 in the outcome phase, a mosaicked movie clip appeared on the screen, regardless of the

5 performance.

To approximately equate the performance in the SID task across participants, we applied an adaptive algorithm that dynamically adjusted the duration of each target presentation as a function of target performance to allow participants to achieve a standardized hit rate of $\sim 66 \%$ (Buckholtz et al. 2010; Kohls et al. 2013; Abe and Greene 2014). To achieve this, the duration of time in which the square appeared in the subsequent trial was shortened in 25-ms increments if the current hit rate exceeded $66 \%$ or lengthened in $25-\mathrm{ms}$ increments if the current hit rate fell below $66 \%$. The duration of the target was set to never fall below $150 \mathrm{~ms}$ or exceed $450 \mathrm{~ms}$. In the first trial for each condition in the session, the target presentation was fixed at $300 \mathrm{~ms}$. The mean hit rate for all participants was $61.9 \%(\mathrm{SD}=4.0 \%)$. We also confirmed that no participants had mean hit rates lower than 3 SD below the mean of all participants $(<50.0 \%)$, which ensured that all participants were seriously engaged in the task.

Rating task and questionnaires. Following the completion of the SID task, the participants performed a rating task outside of the scanner, in which they rated a total of 30 movie clips that showed expressions of positive feedback by the partner, the attractive female, and the unattractive female presented in the hit trials. Each movie clip appeared on the screen for $1500 \mathrm{~ms}$ in a pseudorandom order. The participants were asked to rate the degree of likeability for each clip on a 7-point scale (1: not at all, 7: extremely). A fixation was presented for $1000 \mathrm{~ms}$ following each trial. After completing the rating task, 
1 the participants completed two questionnaires on relationship quality, including

2 relationship commitment and attitudes toward extrapair relationships (see Section 2 in

3 Supplemental Material).

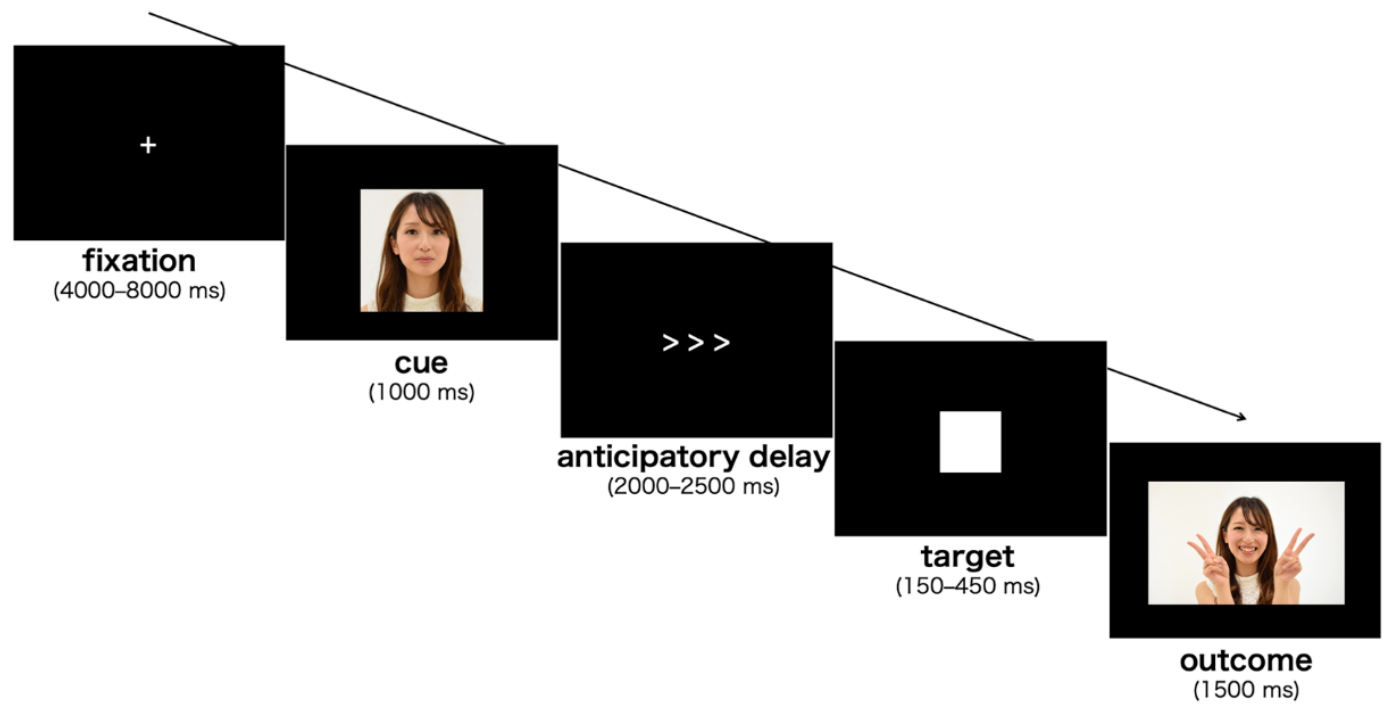

$5 \quad$ Figure 1

6 Schematic of the SID task. This task required the participants to give a simple, rapid

7 response to the target presentation. The presentation of positive feedback from the cued

8 person depended on the participant's performance. In each trial, the participants were

9 shown one of four pictures (cue phase), which indicated the upcoming condition. Each session had four conditions (partner, attractive, unattractive, and control), with ten trials

11 each. The participants were presented with an object indicating the target presentation

12 over a variable interval (anticipatory delay phase), and then they responded to a white

13 target square with a button press. Target hits (i.e., responses that occur during the target

14 stimulus presentation) resulted in a short movie clip presentation of the cued person

15 showing a happy facial expression with a positive gesture (outcome phase). Error

16 responses (i.e., responses that occur in the absence of the target stimulus) resulted in a 
1 short movie clip presentation of the cued person showing a neural facial expression with

2 no gesture. In control condition trials, a mosaicked movie clip appeared on the screen, 3 regardless of the performance. 
$1 \quad$ Image acquisition and analysis

Acquisition parameters and image preprocessing. The participants were scanned using a 3.0-Tesla Siemens Magnetom Verio MRI scanner (Siemens, Erlangen, Germany) with a 32-channel head coil. A T2*-weighted echo-planar imaging (EPI) sequence that was sensitive to blood oxygen level-dependent (BOLD) contrast was used for functional

6 imaging with accelerated multiband acquisitions (Feinberg et al. 2010; Moeller et al.

7 2010; $\mathrm{Xu}$ et al. 2013) that had the following parameters: repetition time $=2000 \mathrm{~ms}$; echo

8 time $=43 \mathrm{~ms}$; flip angle $=80^{\circ}$; acquisition matrix $=96 \times 96$; field of view $=192 \mathrm{~mm}$; in-

9 plane resolution $=2 \times 2 \mathrm{~mm}$; number of axial slices $=76$; slice thickness $=2.0 \mathrm{~mm}$ without interslice gap (interleaved order); and multiband acceleration factor $=4$. A highresolution (spatial resolution $=1 \times 1 \times 1 \mathrm{~mm}$ ) structural image was also acquired with a T1-weighted magnetization-prepared rapid-acquisition gradient echo (MP-RAGE) pulse sequence. Head motion was restricted with firm padding placed around the head. Visual stimuli were projected onto a screen and viewed through a mirror attached to the head coil, and behavioral responses were recorded with a fiber-optic response box. The first five volumes of the 230 volumes collected in each session were discarded to allow for equilibration effects.

Data preprocessing and statistical analyses were performed using SPM12 (Wellcome Department of Imaging Neuroscience, London, UK). For preprocessing, the EPI images were first corrected for slice acquisition time. Then, all images were realigned to correct for small movements between scans. This generated an aligned set of images and a mean image per subject. Each participant's T1-weighted structural MRI was then coregistered to the mean of the realigned EPI images. The coregistered T1 image was normalized to a template image that was based on the Montreal Neurological Institute 
1 (MNI) template using unified segmentation (Ashburner and Friston 2005). The

2 parameters of this normalization process were applied to the EPI images. EPI images

3 were reformatted to isometric voxels $(2 \times 2 \times 2 \mathrm{~mm})$. These normalized but unsmoothed

4 EPI images were used for classification analyses for each participant.

General linear model. We designed a general linear model (GLM) for each

6 participant and each run. The GLM contained four regressors indicating the anticipatory

7 delay phase for the four conditions (partner, attractive, unattractive, and control; duration

$8=2000-2500 \mathrm{~ms}$ ), as well as regressors separately indicating the outcome phase of the

9 four conditions for each hit and miss trial (duration $=1500 \mathrm{~ms}$ ). The GLM also contained an error trials regressor that indicated the delay and outcome phases in the trials in which participants made no response or in those in which they made responses before the target presentation. All regressors were convolved with a canonical hemodynamic response function. In addition, six motion-correction parameters were included as regressors of no interest. A high-pass filter $(1 / 128 \mathrm{~Hz})$ was used to remove low-frequency noise, and a

15 first-order autoregressive (AR(1)) model was employed to correct for temporal 16 autocorrelation. The parameter estimates (betas) for each event were calculated for all 17 brain voxels. The fMRI responses were entered into the classification analysis as 18 classification samples. MVPA. To test whether the anticipation of positive feedback from partners and unfamiliar females can be decoded from patterns of fMRI responses, we performed a classification analysis. We focused on neural responses in the NAcc during the anticipatory delay phase, a critical region for social reward anticipation (Cromwell et al. 2020). Previous studies using the SID task have indicated increased NAcc activation while anticipating more attractive social rewards (Spreckelmeyer et al. 2009; Rademacher 
1 et al. 2010; Kohls et al. 2013). We anatomically defined regions of interest (ROIs) for the

2 left and right NAcc. In addition, we investigated neural responses in the medial

3 orbitofrontal cortex (mOFC), a key region for subjective evaluation of facial

4 attractiveness or preference (O'Doherty et al. 2003; Kranz and Ishai 2006; Ishai 2007;

5 Kim et al. 2007), and white matter as a control region (see Section 3 in Supplemental

6 Material). In the classification analysis, we extracted voxelwise fMRI responses during

7 the anticipatory delay phase and the outcome phase in each condition as classification

8 samples. Then, we employed a linear support vector machine with a cost parameter of C

$9=1$ as a classifier using The Decoding Toolbox (Version 3.994; Hebart et al. 2015). For

each ROI, classification accuracies were estimated using leave-one-run-out cross-

validation. Specifically, a classifier was trained to discriminate experimental conditions

(e.g., partner vs. attractive conditions) from the spatial patterns of brain activity in four runs. Then, the discrimination performance was tested on the remaining run whose data were not used in the training. If the ROI encodes significantly distinguishable neural representations for each condition, the classifier is expected to successfully learn the patterns of the activity during the training and accurately predict the conditions in the new dataset during the testing. This procedure was repeated for all five runs, and we obtained mean accuracy scores across runs for each participant, which allowed us to avoid the problem of overfitting by performing a single test. For each ROI, we examined whether the mean accuracy across participants was greater than chance using a one-sample t-test (one-tailed) to test a directional hypothesis. More specifically, we tested the three-way comparison between partner, attractive, and unattractive conditions (chance $=33.3 \%$ ). Planned one-tailed t-tests on mean classification accuracy in the comparison with the chance have been widely employed in previous studies of MVPA (e.g., Skerry and Saxe 
1 2014; Seymour et al. 2015; Dungan et al. 2016; Loose et al. 2017; Suzuki et al. 2017). If

2 neural activities within the ROI do not demonstrate dissociable patterns between these

3 three conditions, classification performances should be at chance level. If above-chance

4 performance was observed in the three-way comparison, we continued to test all possible

5 pairs (partner vs. attractive, partner vs. unattractive, and attractive vs. unattractive; chance

$6=50 \%$ ). In this post hoc pairwise test, we report adjusted p-values with Bonferroni

7 correction (i.e., adjusted $\mathrm{p}$-value $=\mathrm{p}$-value multiplied by 3 ) to control the familywise error

8 rate of multiple comparisons, unless otherwise specified. 


\section{$1 \quad$ Results}

2 Behavioral data

3 All of the statistical analyses were performed with R version 3.5.3 (R Core Team 2019).

4 Statistical tests were two-tailed, except one-tailed tests to determine whether mean 5 classification accuracy across participants was greater than chance (see Materials and 6 Methods). For t-tests, we calculated the effect size, Cohen's d with Hedges's correction 7 using the "effsize" package version 0.8.1 implemented with R (Torchiano 2020).

We performed one-way ANOVA on response times to the target presentation in 9 the SID task, taking condition (partner, attractive, unattractive, and control) as a withinsubject factor, and found a significant main effect of condition $(F(3,111)=22.80, p<$ $0.001, \eta_{\mathrm{p}}{ }^{2}=0.38$; Figure $2 \mathrm{~A}$ ). Post hoc t-tests with adjusted $\mathrm{p}$-values with Bonferroni correction (i.e., adjusted $\mathrm{p}$-value $=\mathrm{p}$-value multiplied by 6 ) indicated that the participants tended to respond significantly more quickly in the partner condition than in the other three conditions (partner vs. attractive: $\mathrm{p}<0.001, \mathrm{~d}=0.29$; partner vs. unattractive: $\mathrm{p}<$ $0.001, \mathrm{~d}=0.47$; partner vs. control: $\mathrm{p}<0.001, \mathrm{~d}=0.42$ ). The participants also responded significantly more quickly in the attractive condition than in the unattractive condition ( $p$ $=0.002, \mathrm{~d}=0.21)$. These results were consistent with those of previous studies showing that the anticipation of more attractive feedback elicited a more rapid response (Spreckelmeyer et al. 2009; Rademacher et al. 2010; Kohls et al. 2013).

We then performed one-way ANOVA on the likeability ratings for the movie clips with happy expressions in the rating task outside the scanner with condition (partner, attractive, and unattractive) as a within-subject factor and found a significant main effect for condition $\left(F(2,74)=109.20, p<0.001, \eta_{p}{ }^{2}=0.75\right.$; Figure $\left.2 B\right)$. Post hoc t-tests with adjusted p-values with Bonferroni correction (i.e., adjusted $\mathrm{p}$-value $=$ p-value multiplied 
1 by 3 ) indicated that the participants had greater preference for their partner's clips over 2 attractive and unattractive unfamiliar females' clips (partner vs. attractive: $p=0.007, d=$ 3 0.71; partner vs. unattractive: $\mathrm{p}<0.001, \mathrm{~d}=3.07$ ). The participants also exhibited a 4 greater preference for the clips with the attractive female than those with the unattractive 5 female $(p<0.001, d=2.22)$, which indicated a successful manipulation of stimuli. We

6 further confirmed that greater preference for the partner's movie clips over the attractive

7 nonpartner was observed only in the fMRI participants, not in an independent participant 8 group (see Section 4 in Supplemental Material). 
1
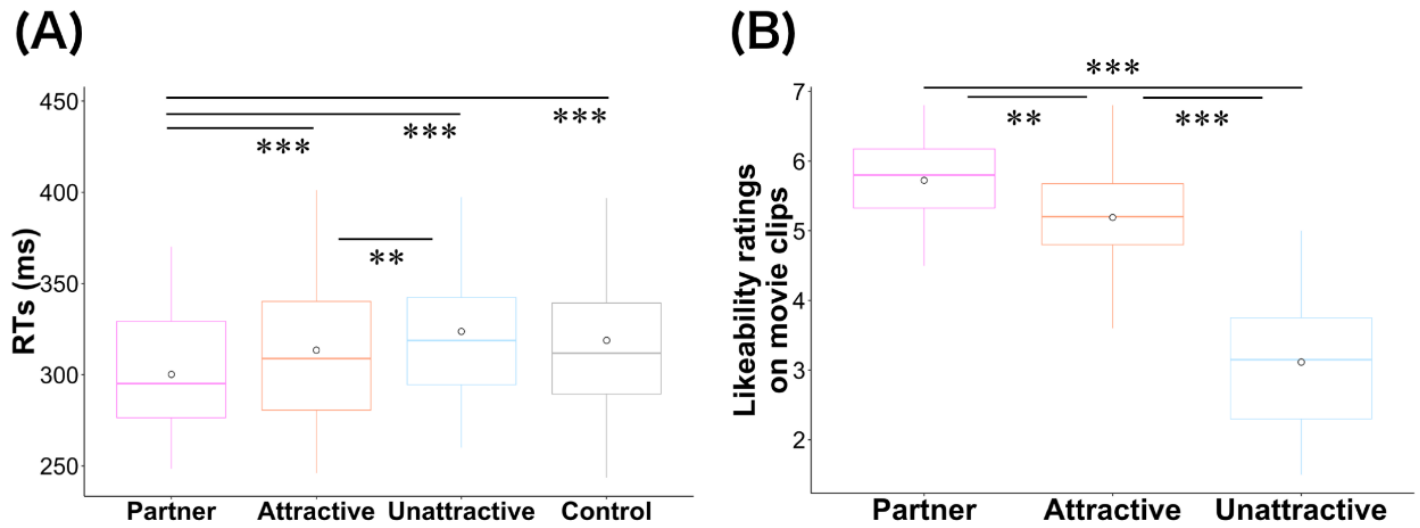

$2 \quad$ Figure 2

3 (A) Response times (RTs) to the target presentation in the SID task and (B) likeability

4 ratings for the happy-expression movie clips presented in the SID task. In each box and

5 whisker plot, the central line denotes the median, and the bottom and top hinges of the

6 box indicate the 25 th and 75 th percentiles, respectively. The upper whisker extends to the

7 largest value no further than 1.5 times the interquartile range (IQR) from the hinge, and

8 the lower whisker extends to the smallest value no further than 1.5 times the IQR from

9 the hinge. White dots indicate mean values across participants. ${ }^{* * *} \mathrm{p}<0.001,{ }^{* *} \mathrm{p}<0.01$ 
1

2

3

\section{fMRI data}

\section{MVPA for the anticipatory delay phase}

We assessed whether the NAcc encoded unique representations of anticipated positive feedback from the partner. The classification analyses of the three-way comparison across the conditions for partner, attractive, and unattractive during the anticipatory delay phase $($ chance $=33.3 \%$ ) showed above-chance classification performances both in the left and right NAcc (left: mean accuracy across participants $=38.6 \%, \mathrm{SD}=13.7 \%, \mathrm{t}(37)=2.38$, adjusted $\mathrm{p}=0.022, \mathrm{~d}=0.38$, lower $95 \%$ confidence interval $(\mathrm{CI})=34.8 \%$; right: mean $=$ $40.7 \%, \mathrm{SD}=16.6 \%, \mathrm{t}(37)=2.75$, adjusted $\mathrm{p}=0.009, \mathrm{~d}=0.44$, lower $95 \% \mathrm{CI}=36.2 \%$, one-tailed; p-values were multiplied by 2). As the paired t-test indicated no significant differences in these mean accuracies between the left and right NAcc $(\mathrm{t}(37)=-0.62, \mathrm{p}=$ $0.54, \mathrm{~d}=0.14,95 \% \mathrm{CI}=[-8.94,4.73])$, we report averaged accuracies (i.e., mean of the left and right NAcc) hereafter unless otherwise specified. We confirmed that this averaged accuracy for the three-way comparison was also above chance (mean $=39.6 \%$, $\mathrm{SD}=11.1 \%, \mathrm{t}(37)=3.52, \mathrm{p}<0.001, \mathrm{~d}=0.56$, lower $95 \% \mathrm{CI}=36.6 \%$, one-tailed). Similar results were observed when the control condition was included (four-way comparison across the conditions for partner, attractive, unattractive, and control: chance $=25 \%$; mean $=30.5 \%, \mathrm{SD}=10.8 \%, \mathrm{t}(37)=3.17, \mathrm{p}=0.002, \mathrm{~d}=0.50$, lower $95 \% \mathrm{CI}=27.6 \%$, one-tailed; see also Section 5 in Supplemental Material).

Additional pairwise analyses revealed dissociable neural representations between the partner and nonpartner conditions (chance $=50 \%$, adjusted $p$-value $=p$-value multiplied by 3 ; Figure 3); that is, we observed significantly higher classification accuracies over the chance level in both partner vs. attractive conditions (mean $=58.7 \%$, $\mathrm{SD}=13.6 \%, \mathrm{t}(37)=3.94$, adjusted $\mathrm{p}<0.001, \mathrm{~d}=0.63$, lower $95 \% \mathrm{CI}=55.0 \%$, one- 
1 tailed) and partner vs. unattractive conditions (mean $=59.7 \%, \mathrm{SD}=17.9 \%, \mathrm{t}(37)=3.35$,

2 adjusted $\mathrm{p}=0.003, \mathrm{~d}=0.53$, lower $95 \% \mathrm{CI}=54.8 \%$, one-tailed). We further explored

3 whether individual differences in the NAcc activity patterns during anticipating feedback

4 from the partner were associated with relationship commitment and attitudes toward

5 extrapair relationships (see Sections 6 and 7 in the Supplemental Material). However, as

6 the sample size of the present study is not enough to provide adequate power for the

7 across-participant correlation tests, we refrain from discussing those results.

In the white matter control region, we did not observe classification performance

9 better than chance in the three-way comparison (chance $=33.3 \%$; mean $=29.8 \%, \mathrm{SD}=$

$10 \quad 14.3 \%, \mathrm{t}(37)=-1.50, \mathrm{p}=0.93, \mathrm{~d}=0.24$, lower $95 \% \mathrm{CI}=25.9 \%$, one-tailed). 


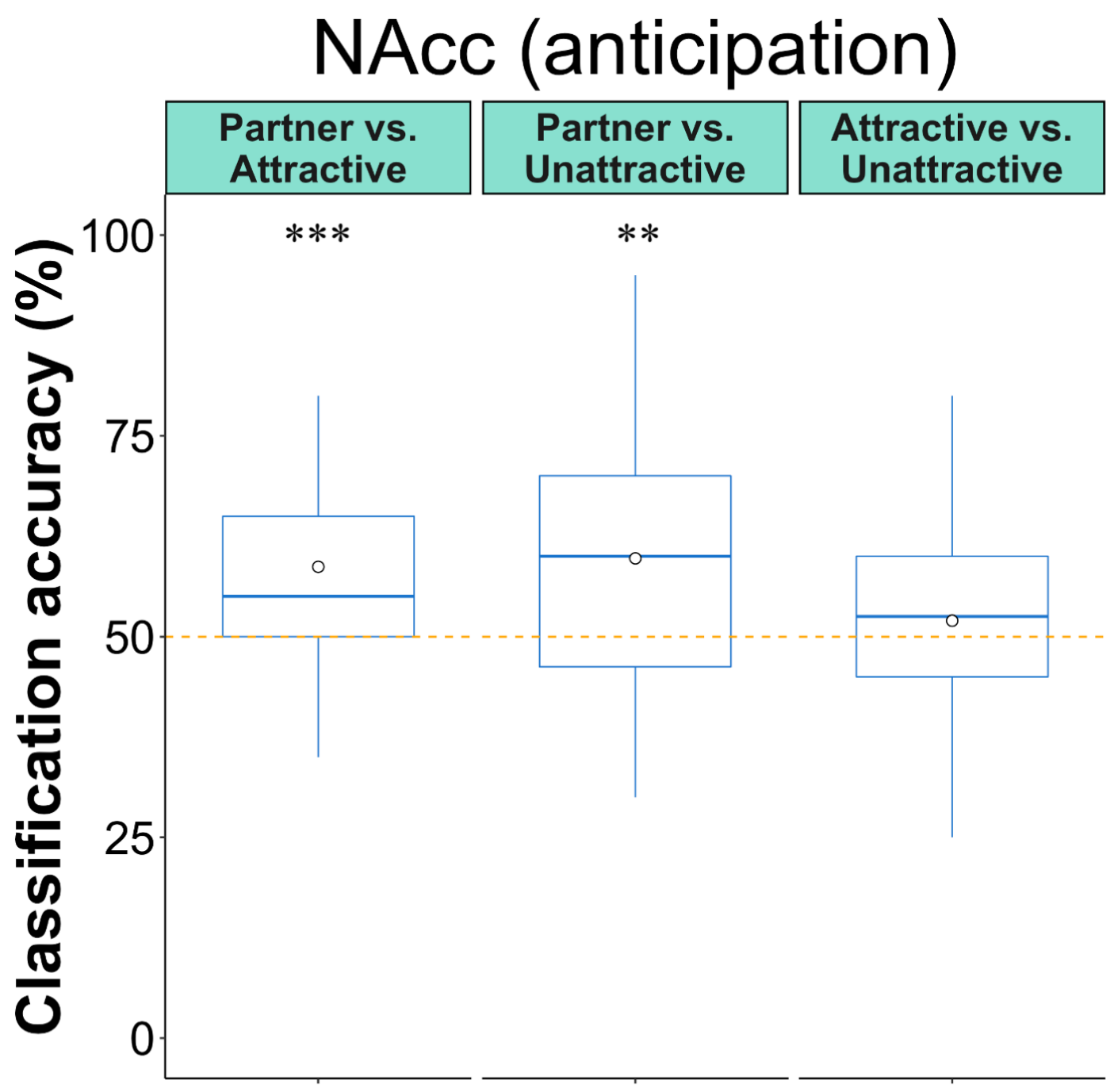

$2 \quad$ Figure 3

3 Results of the classification analysis for the nucleus accumbens (NAcc) during the

4 anticipatory delay phase, illustrating mean accuracies of the left and right NAcc. Box and

5 whisker plots with white dots are as defined in Figure 2. A classification accuracy better

6 than chance was determined using a one-sample t-test vs. $50 \%$ (one-tailed). ${ }^{* * *} \mathrm{p}<0.001$,

$7 \quad{ }^{* *} \mathrm{p}<0.01$ 
2 In the comparison between the attractive and unattractive conditions, above-chance

3 differences in classification performance were not observed in the NAcc during the 4 anticipatory delay phase $($ mean $=52.0 \%, \mathrm{SD}=12.8 \%, \mathrm{t}(37)=0.95$, adjusted $\mathrm{p}=0.52, \mathrm{~d}$ $5=0.15$, lower $95 \% \mathrm{CI}=48.5 \%$, one-tailed; Figure 3 ). It might be thought that this was 6 because the participants were not attracted to the attractive model. However, this 7 explanation is inconsistent with behavioral data showing a greater preference for 8 attractive females than unattractive females. One alternative explanation for the null 9 finding is that this information could be decodable during the outcome phase rather than the anticipatory delay phase. Numerous studies have reported the involvement of the NAcc and mOFC in the positive social evaluation of faces (Aharon et al. 2001; O'Doherty et al. 2003; Kranz and Ishai 2006; Ishai 2007; Kim et al. 2007; Bzdok et al. 2011; MendeSiedlecki et al. 2013; Ueda et al. 2017). Kim et al. (2007) suggested functional dissociations between these regions in reward processing, such that the NAcc conveys information on the reward to the orbitofrontal cortex, which underlies subjective evaluation processes. A meta-analysis study of the monetary incentive delay task also suggested that the mOFC represents the value of the reward received rather than anticipation of the reward (Oldham et al. 2018). These findings lead us to predict that neural activity patterns in the mOFC could be more sensitive to differences in attractive and unattractive females than in the NAcc, especially during the outcome phase, which could involve an evaluation of the presented stimulus.

Consistent with this prediction, we observed above-chance classification performance in the mOFC (mean of the left and right) during the outcome phase in a three-way comparison across partner-hit, attractive-hit, and unattractive-hit conditions 
$1 \quad($ chance $=33.3 \% ;$ mean $=38.4 \%, \mathrm{SD}=10.3 \%, \mathrm{t}(37)=3.06, \mathrm{p}=0.002, \mathrm{~d}=0.49$, lower

$295 \% \mathrm{CI}=35.6 \%$ ). As in the NAcc during the anticipatory delay phase, we found no

3 significant differences in the mean accuracies for this three-way comparison between the

$4 \quad$ left $($ mean $=39.1 \%, \mathrm{SD}=15.5 \%)$ and right $($ mean $=37.7 \%, \mathrm{SD}=14.6 \%)$ mOFCs $(\mathrm{t}(37)$

$5=0.39, \mathrm{p}=0.70, \mathrm{~d}=0.09,95 \% \mathrm{CI}=[-5.84,8.65])$. We also observed above-chance

6 classification performance in a four-way comparison including the control-hit condition

$7 \quad($ chance $=25 \%$; mean $=34.3 \%, \mathrm{SD}=7.7 \%, \mathrm{t}(37)=7.44, \mathrm{p}<0.001, \mathrm{~d}=1.18$, lower $95 \%$

$8 \mathrm{CI}=32.2 \%$, one-tailed; see also Section 8 in Supplemental Material). Pairwise analysis

$9 \quad$ (adjusted $p$-value $=$ p-value multiplied by 3; Figure 4) revealed an above-chance difference in classification performance in the attractive-hit vs. unattractive-hit conditions $($ chance $=50 \% ;$ mean $=55.0 \%, \mathrm{SD}=11.9 \%, \mathrm{t}(37)=2.59$, adjusted $\mathrm{p}=0.021, \mathrm{~d}=0.41$, lower $95 \% \mathrm{CI}=51.7 \%$, one-tailed). We also observed higher mean classification accuracy over the chance level for the comparisons between the partner-hit and unattractive-hit conditions $($ mean $=62.1 \%, \mathrm{SD}=12.9 \%, \mathrm{t}(37)=5.77$, adjusted $\mathrm{p}<0.001$, $\mathrm{d}=0.92$, lower $95 \% \mathrm{CI}=58.6 \%$, one-tailed); however, above-chance performance was not observed for the classification between the partner-hit and attractive-hit conditions $($ mean $=53.0 \%, \mathrm{SD}=15.7 \%, \mathrm{t}(37)=1.19$, adjusted $\mathrm{p}=0.36, \mathrm{~d}=0.19$, lower $95 \% \mathrm{CI}=$ 48.7\%, one-tailed), which likely reflected smaller differences in likeability ratings between the partner and attractive conditions relative to those between the partner and unattractive conditions (Figure 2B). differences in classification performance in the outcome phase for the NAcc in the threeway comparison $($ chance $=33.3 \%$; mean $=35.8 \%, \mathrm{SD}=10.0 \%, \mathrm{t}(37)=1.53, \mathrm{p}=0.067$, $d=0.24$, lower $95 \% C I=33.1 \%$, one-tailed). Here, the critical test for this asymmetry 
1 was to determine whether a region x phase interaction was significant. Two-way ANOVA

2 on classification performances with region (NAcc and $\mathrm{mOFC}$ ) and phase (anticipatory

3 delay and outcome) as the within-subject factors revealed a significant interaction $(\mathrm{F}(1$,

$\left.4 \quad 37)=7.73, p=0.009, \eta_{p}^{2}=0.17\right)$. 


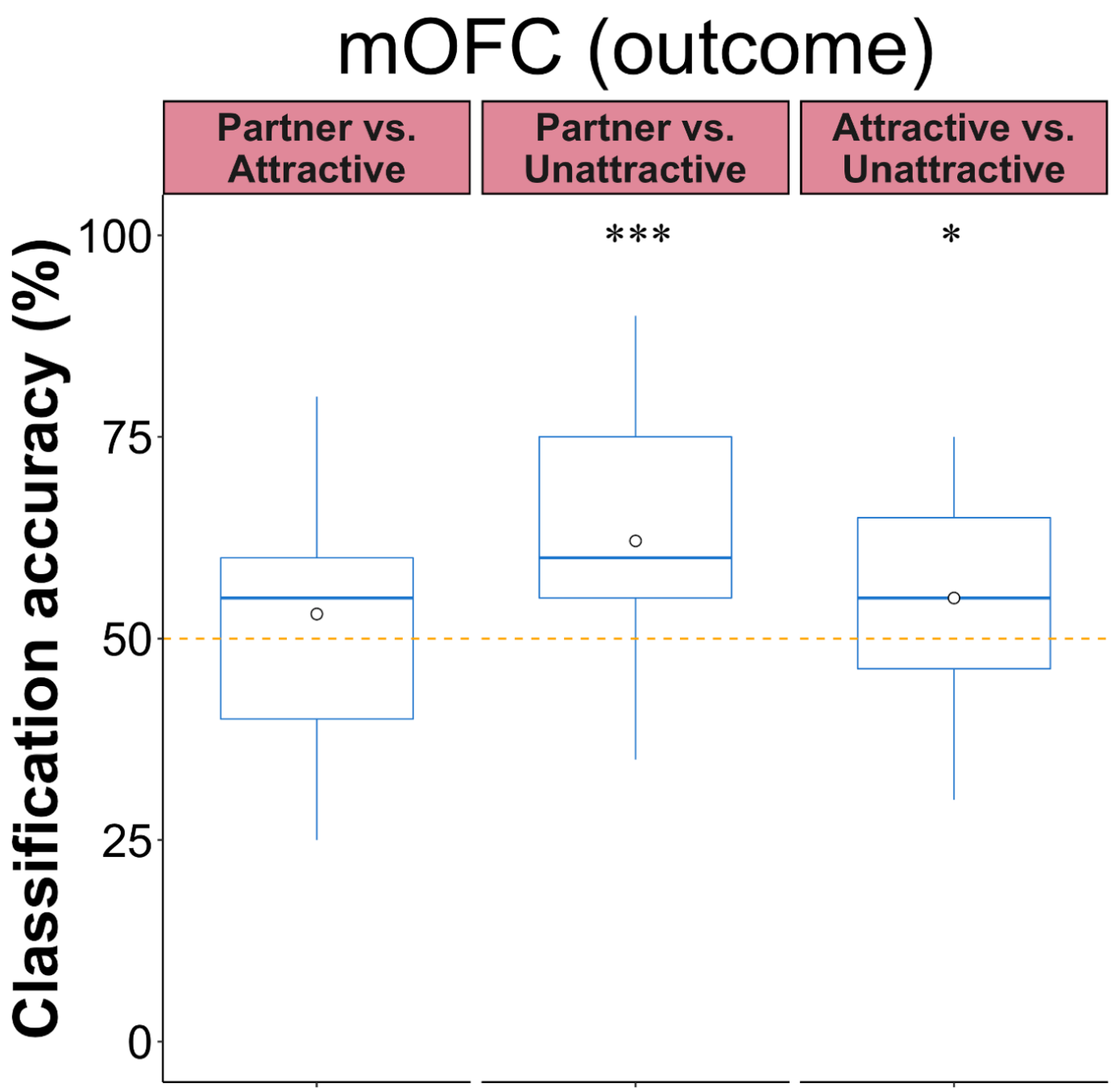

$2 \quad$ Figure 4

3 Results of the classification analysis for the medial orbitofrontal cortex (mOFC) during

4 the outcome phase, illustrating mean accuracies of the left and right mOFC. Box and

5 whisker plots with white dots are as defined in Figure 2. A classification accuracy better

6 than chance was determined using a one-sample t-test vs. $50 \%$ (one-tailed). ${ }^{* * *} \mathrm{p}<0.001$,

$7 \quad{ }^{*} \mathrm{p}<0.05$ 


\section{Discussion}

2 While there has been a consensus that reward circuitry underlies romantic attachment

3 toward a committed partner, it is unclear whether this is encoded in a dissociable way

4 from a general preference for attractive opposite-sex individuals. Numerous studies have

5 reported biased behaviors that could contribute to relationship maintenance shown by

6 romantically involved individuals; therefore, we expected to observe distinct neural

7 representations in the NAcc between the committed partner and other opposite-sex

8 individuals. Using MVPA and the SID task, we found unique neural activity patterns in

9 the NAcc when positive feedback from the committed partner was anticipated.

The classification approach used in the present study allowed us to clarify unique neural representations in the NAcc related to the romantic partner, which could extend previous findings on the neural basis for emotional bonding with the partner, identified using conventional univariate fMRI (Fisher et al. 2010; Acevedo et al. 2012). Our results are consistent with previous studies showing the NAcc as a crucial region for establishing both selective preferences toward the committed partner and avoidance behavior toward alternative partners both in human and nonhuman monogamous animals (Young and Wang 2004; Scheele et al. 2012, 2013, 2016; Kreuder et al. 2017; Walum and Young 2018). The present findings for the NAcc also fit well with a theoretical framework of the automatic regulation of amorous temptation via emotional bonding with a partner (Finkel and Eastwick 2015; Fletcher et al. 2015; Lydon and Karremans 2015).

Another notable finding was that the mOFC differentially encoded positive feedback from attractive females and unattractive females, while the NAcc did not during anticipation of the feedback. These results imply that neural activity patterns in the mOFC could be more sensitive to differences in attractive and unattractive females than in the 
1 NAcc, especially during the outcome phase, which could involve an evaluation of the

2 presented stimulus. These findings provide tentative support for the idea of functional

3 dissociation in the NAcc and $\mathrm{mOFC}$ in the domain of reward anticipation and receipt (e.g.,

4 Kim et al., 2007; Oldham et al. 2018), which contributes to explaining the lack of

5 differences in the NAcc classification accuracy between attractive and unattractive

6 females during the anticipatory phase.

$7 \quad$ In this study, we aimed to reveal whether the NAcc encodes emotional bonding

8 with the committed partner differently from an interest in new relationships. To this end,

9 we used movie clips and pictures of unfamiliar opposite-sex individuals instead of those of familiar individuals. Therefore, our findings cannot rule out the possibility that the effects observed in the present study reflect differences in other variables, such as saliency or familiarity of each person. Future studies should extend our findings by testing whether neural representations of emotional bonding with committed partners could be dissociable from the romantic interest in familiar nonpartners (e.g., opposite-sex friends to whom the romantically involved individual is attracted). In such an investigation, implicit measures would be more desirable to avoid potential confounding effects, including concern for social desirability, by explicitly demonstrating romantic interest in nonpartners. Applying MVPA to neural data obtained from sophisticated experimental procedures, such as a visual attention task (Miller 1997; Maner et al. 2007), might allow us to reveal how the NAcc encodes such implicit romantic interest in familiar nonpartners. We discuss the other possible future directions in Section 9 in Supplemental Material. the classification approach does not tell us what kinds of information are included in the neural representations. Unique neural representations related to the partner might involve 
1 distinctively perceived attractiveness to that person, or it might involve more general

2 likeability to that person. To address this issue, representational similarity analysis (RSA,

3 Kriegeskorte et al. 2008; Kriegeskorte and Kievit 2013; Popal et al. 2019) would be

4 suitable, which can assess higher-order representational space across multiple dimensions.

5 Second, as we focused only on individuals in nonmarital dating relationships, it remains

6 unclear whether our findings are generalizable to relationships involving marriage. We

$7 \quad$ leave these questions as topics for future research.

8 In conclusion, we found that the NAcc encodes distinctive neural representations

9 of the committed partner and unfamiliar attractive nonpartners using a classification

10 approach. To the best of our knowledge, the present study is the first to directly

11 demonstrate unique neural representations related to the committed partner, which might

12 be a key neural mechanism for single-minded romantic relationships. 
1

2

\section{References}

Abe, N., \& Greene, J.D. (2014). Response to anticipated reward in the nucleus accumbens predicts behavior in an independent test of honesty. J Neurosci 34:10564-10572. Acevedo, B.P., Aron, A., Fisher, H.E., \& Brown, L.L. (2012). Neural correlates of longterm intense romantic love. Soc Cogn Affect Neurosci 7:145-159.

Aharon, I., Etcoff, N., Ariely, D., Chabris, C.F., O'Connor, E., \& Breiter, H.C. (2001). Beautiful faces have variable reward value: fMRI and behavioral evidence. Neuron 32:537-551.

Aron, A., Fisher, H., Mashek, D.J., Strong, G., Li, H., \& Brown, L.L. (2005). Reward, motivation, and emotion systems associated with early-stage intense romantic love. J Neurophysiol 94:327-337.

Ashburner, J., \& Friston, K. J. (2005). Unified segmentation. Neuroimage, 26:839-851.

Barelds, D.P.H., Dijkstra, P., Koudenburg, N., \& Swami, V. (2011). An assessment of positive illusions of the physical attractiveness of romantic partners. J Soc Pers Relat 28:706-719.

Barelds-Dijkstra, P., \& Barelds, D.P.H. (2008). Positive illusions about one's partner's physical attractiveness. Body Image 5:99-108.

Bartels, A., \& Zeki, S. (2000). The neural basis of romantic love. Neuroreport 11:38293834.

Buckholtz, J.W., Treadway, M.T., Cowan, R.L., Woodward, N.D., Benning, S.D., Li, R., Ansari, M.S., Baldwin, R.M., Schwartzman, A.N., Shelby, E.S., Smith, C.E., Cole, D., Kessler, R.M., \& Zald, D.H. (2010). Mesolimbic dopamine reward system hypersensitivity in individuals with psychopathic traits. Nat Neurosci 13:419-421. Buss, D.M., \& Schmitt, D.P. (1993). Sexual strategies theory: An evolutionary 
perspective on human mating. Psychol Rev 100:204-232.

Bzdok, D., Langner, R., Caspers, S., Kurth, F., Habel, U., Zilles, K., Laird, A., \& Eickhoff, S.B. (2011). ALE meta-analysis on facial judgments of trustworthiness and attractiveness. Brain Struct Funct 215:209-223.

Cohen, J.D., Daw, N., Engelhardt, B., Hasson, U., Li, K., Niv, Y., Norman, K.A., Pillow, J., Ramadge, P.J., Turk-Browne, N.B., \& Willke, T.L. (2017). Computational approaches to fMRI analysis Nat Neurosci 20:304-313.

Cromwell, H.C., Abe, N., Barrett, K.C., Caldwell-Harris, C., Gendolla, G.H.E., Koncz, R., \& Sachdev, P.S. (2020). Mapping the interconnected neural systems underlying motivation and emotion: A key step toward understanding the human affectome. Neurosci Biobehav Rev 113:204-226.

Diener, E., Suh, E.M., Lucas, R.E., \& Smith, H.L. (1999). Subjective well-being: Three decades of progress. Psychol Bull 125:276-302.

Dungan, J.A., Stepanovic, M., \& Young, L. (2016). Theory of mind for processing unexpected events across contexts. Soc Cogn Affect Neurosci 11:1183-1192.

Faul, F., Erdfelder, E., Lang, A.G., \& Buchner, A. (2007). G*Power 3: A flexible statistical power analysis program for the social, behavioral, and biomedical sciences. Behav Res Methods 39:175-191.

Faul, F., Erdfelder, E., Buchner, A., \& Lang, A.G. (2009). Statistical power analyses using G*Power 3.1: Tests for correlation and regression analyses. Behav Res Methods 41:1149-1160.

Feinberg, D.A., Moeller, S., Smith, S.M., Auerbach, E., Ramanna, S., Gunther, M., Glasser, M.F., Miller, K.L., Ugurbil, K., \& Yacoub, E. (2010). Multiplexed echo planar imaging for sub-second whole brain fMRI and fast diffusion imaging. 
PLoS One 5:e15710.

Finkel, E.J., \& Eastwick, P.W. (2015). Attachment and pairbonding. Curr Opin Behav Sci $3: 7-11$.

Fisher, H. (2004). Why we love: The nature and chemistry of romantic love. New York: Henry Holt.

Fisher, H.E., Brown, L.L., Aron, A., Strong, G., \& Mashek, D. (2010). Reward, addiction, and emotion regulation systems associated with rejection in love. J Neurophysiol 104:51-60.

Fletcher, G.J.O., Simpson, J.A., Campbell, L., \& Overall, N.C. (2015). Pair-bonding, romantic love, and evolution: The curious case of Homo sapiens. Perspect Psychol Sci 10:20-36.

Furman, W. (2002). The emerging field of adolescent romantic relationships. Curr Dir Psychol Sci 11:177-180.

Haxby, J.V., Connolly, A.C., \& Guntupalli, J.S. (2014). Decoding neural representational spaces using multivariate pattern analysis. Annu Rev Neurosci 37:435-456.

Hebart, M.N., Gorgen, K., \& Haynes, J.D. (2015). The Decoding Toolbox (TDT): A versatile software package for multivariate analyses of functional imaging data. Front Neuroinform 8:88.

Holmes, T.H., \& Rahe, R.H. (1967). The social readjustment rating scale. J Psychosom Res 11:213-218.

House, J.S., Landis, K.R., \& Umberson, D. (1988). Social relationships and health. Science 241:540-545.

Ishai, A. (2007). Sex, beauty and the orbitofrontal cortex. Int J Psychophysiol 63:181-185. Jankowiak, W.R., \& Fischer, E.F. (1992). A cross-cultural perspective on romantic love. 
Ethnology 31:149-155.

Johnson, D.J., \& Rusbult, C.E. (1989). Resisting temptation: Devaluation of alternative partners as a means of maintaining commitment in close relationships. J Pers Soc Psychol 57:967-980.

Kiecolt-Glaser, J.K., \& Newton, T.L. (2001). Marriage and health: His and hers. Psychol Bull 127:472-503.

Kim, H., Adolphs, R., O'Doherty, J.P., \& Shimojo, S. (2007). Temporal isolation of neural processes underlying face preference decisions. Proc Natl Acad Sci U S A 104:18253-18258.

Knutson, B., Westdorp, A., Kaiser, E., \& Hommer, D. (2000). FMRI visualization of brain activity during a monetary incentive delay task. Neuroimage 12:20-27.

Kohls, G., Perino, M.T., Taylor, J.M., Madva, E.N., Cayless, S.J., Troiani, V., Price, E., Faja, S., Herrington, J.D., \& Schultz, R.T. (2013). The nucleus accumbens is involved in both the pursuit of social reward and the avoidance of social punishment. Neuropsychologia 51:2062-2069.

Kranz, F., \& Ishai, A. (2006). Face perception is modulated by sexual preference. Curr Biol 16:63-68.

Kreuder, A.K., Scheele, D., Wassermann, L., Wollseifer, M., Stoffel-Wagner, B., Lee, M.R., Hennig, J., Maier, W., \& Hurlemann, R. (2017). How the brain codes intimacy: The neurobiological substrates of romantic touch. Hum Brain Mapp $38: 4525-4534$.

Kriegeskorte, N., Mur, M., \& Bandettini, P. (2008). Representational similarity analysisconnecting the branches of systems neuroscience. Front Syst Neurosci 2:4.

Kriegeskorte, N., \& Kievit, R.A. (2013). Representational geometry: Integrating 
cognition, computation, and the brain. Trends Cogn Sci 17:401-412.

Loose, L.S., Wisniewski, D., Rusconi, M., Goschke, T., \& Haynes, J.D. (2017). Switchindependent task representations in frontal and parietal cortex. J Neurosci $37: 8033-8042$.

Lydon, J., \& Karremans, J.C. (2015). Relationship regulation in the face of eye candy: A motivated cognition framework for understanding responses to attractive alternatives. Curr Opin Psychol 1:76-80.

Maner, J.K., Gailliot, M.T., Rouby, D.A., \& Miller, S.L. (2007). Can't take my eyes off you: Attentional adhesion to mates and rivals. J Pers Soc Psychol 93:389-401.

Maner, J.K., Rouby, D.A., \& Gonzaga, G.C. (2008). Automatic inattention to attractive alternatives: The evolved psychology of relationship maintenance. Evol Hum Behav 29:343-349.

Maner, J.K., Gailliot, M.T., \& Miller, S.L. (2009). The implicit cognition of relationship maintenance: Inattention to attractive alternatives. J Exp Soc Psychol 45:174-179.

Mende-Siedlecki, P., Said, C.P., \& Todorov, A. (2013). The social evaluation of faces: A meta-analysis of functional neuroimaging studies. Soc Cogn Affect Neurosci $8: 285-299$.

Miller, R.S. (1997). Inattentive and contented: Relationship commitment and attention to alternatives. J Pers Soc Psychol 73:758-766.

Moeller, S., Yacoub, E., Olman, C.A., Auerbach, E., Strupp, J., Harel, N., \& Ugurbil, K. (2010). Multiband multislice GE-EPI at 7 tesla, with 16-fold acceleration using partial parallel imaging with application to high spatial and temporal whole-brain fMRI. Magn Reson Med 63:1144-1153.

Murray, S.L., \& Holmes, J.G. (1997). A leap of faith? Positive illusions in romantic 
relationships. Pers Soc Psychol B 23:586-604.

Murray, S.L., Holmes, J.G., \& Griffin, D.W. (1996). The benefits of positive illusions: Idealization and the construction of satisfaction in close relationships. J Pers Soc Psychol 70:79-98.

Norman, K.A., Polyn, S.M., Detre, G.J., \& Haxby, J.V. (2006). Beyond mind-reading: Multi-voxel pattern analysis of fMRI data. Trends Cogn Sci 10:424-430.

O'Doherty, J., Winston, J., Critchley, H., Perrett, D., Burt, D.M., \& Dolan, R.J. (2003). Beauty in a smile: The role of medial orbitofrontal cortex in facial attractiveness. Neuropsychologia 41:147-155.

Oldham, S., Murawski, C., Fornito, A., Youssef, G., Yucel, M., Lorenzetti, V. (2018). The anticipation and outcome phases of reward and loss processing: A neuroimaging meta-analysis of the monetary incentive delay task. Hum Brain Mapp 39:33983418.

Peelen, M.V., \& Downing, P.E. (2007). Using multi-voxel pattern analysis of fMRI data to interpret overlapping functional activations. Trends Cogn Sci 11:4-5.

Popal, H., Wang, Y., \& Olson, I.R. (2019). A guide to representational similarity analysis for social neuroscience. Soc Cogn Affect Neurosci 14:1243-1253.

R Core Team. (2019). R: A language and environment for statistical computing (version 3.5.3). $\mathrm{R}$ Foundation for Statistical Computing, Vienna, Austria. URL https://www.R-project.org/.

Rademacher, L., Krach, S., Kohls, G., Irmak, A., Grunder, G., \& Spreckelmeyer, K.N. (2010). Dissociation of neural networks for anticipation and consumption of monetary and social rewards. Neuroimage 49:3276-3285.

Seymour, K.J., Williams, M.A., \& Rich, A.N. (2015). The representation of color across 
the human visual cortex: Distinguishing chromatic signals contributing to object form versus surface color. Cereb Cortex 26:1997-2005.

Scheele, D., Plota, J., Stoffel-Wagner, B., Maier, W., \& Hurlemann, R. (2016). Hormonal contraceptives suppress oxytocin-induced brain reward responses to the partner's face. Soc Cogn Affect Neurosci 11:767-774.

Scheele, D., Striepens, N., Gunturkun, O., Deutschlander, S., Maier, W., Kendrick, K.M., \& Hurlemann, R. (2012). Oxytocin modulates social distance between males and females. J Neurosci 32:16074-16079.

Scheele, D., Wille, A., Kendrick, K.M., Stoffel-Wagner, B., Becker, B., Gunturkun, O., Maier, W., \& Hurlemann, R. (2013). Oxytocin enhances brain reward system responses in men viewing the face of their female partner. Proc Natl Acad Sci U S A 110:20308-20313.

Scott, E.S. (2000). Social norms and the legal regulation of marriage. Virginial Law Rev 86:1901-1970.

Simpson, J.A., Gangestad, S.W., \& Lerma, M. (1990). Perception of physical attractiveness: Mechanisms involved in the maintenance of romantic relationships. J Pers Soc Psychol 59:1192-1201.

Skerry, A.E., \& Saxe, R. (2014). A common neural code for perceived and inferred emotion. J Neurosci 34:15997-16008.

Spreckelmeyer, K.N., Krach, S., Kohls, G., Rademacher, L., Irmak, A., Konrad, K., Kircher, T., \& Grunder, G. (2009). Anticipation of monetary and social reward differently activates mesolimbic brain structures in men and women. Soc Cogn Affect Neurosci 4:158-165.

Suzuki, S., Cross, L., \& O'Doherty, J.P. (2017). Elucidating the underlying components 
of food valuation in the human orbitofrontal cortex. Nat Neurosci 20:1780-1786.

2 Torchiano, M. (2020). effsize: Efficient effect size computation (version 0.8.1) (software) https://github.com/mtorchiano/effsize/

Uchino, B.N., Cacioppo, J.T., \& Kiecolt-Glaser, J.K. (1996). The relationship between social support and physiological processes: A review with emphasis on underlying mechanisms and implications for health. Psychol Bull 119:488-531.

Ueda, R., Ashida, H., Yanagisawa, K., \& Abe, N. (2017). The neural basis of individual differences in mate poaching. Soc Neurosci 12:391-399.

Walum, H., \& Young, L.J. (2018). The neural mechanisms and circuitry of the pair bond. Nat Rev Neurosci 19:643-654.

Wiederman, M.W. (1997). Extramarital sex: Prevalence and correlates in a national survey. J Sex Res 34:167-174.

Xu, J., Moeller, S., Auerbach, E.J., Strupp, J., Smith, S.M., Feinberg, D.A., Yacoub, E., \& Ugurbil, K. (2013). Evaluation of slice accelerations using multiband echo planar imaging at 3 T. Neuroimage 83:991-1001.

Xu, X., Aron, A., Brown, L., Cao, G., Feng, T., \& Weng, X. (2011). Reward and motivation systems: A brain mapping study of early-stage intense romantic love in Chinese participants. Hum Brain Mapp 32:249-257.

Young, L.J., \& Wang, Z. (2004). The neurobiology of pair bonding. Nat Neurosci 7:10481054.

Zeki, S., \& Romaya, J.P. (2010). The brain reaction to viewing faces of opposite- and same-sex romantic partners. PLoS One 5:e15802. 


\section{Supplemental Material}

\section{1. Stimuli used in the social reward incentive delay task}

3 The participants were engaged in the social reward incentive delay (SID) task, which

4 assesses the neural responses that underlie the anticipation of positive feedback from a

5 cued person. The SID task had four conditions: partner female, attractive female,

6 unattractive female, and control. Similar to a previous study (Kohls et al. 2013), we

7 prepared facial pictures and short movie clips for each person as stimuli. The stimuli

8 presented in the partner condition were unique to each participant (i.e., the participant's

9 current partner's facial picture and movie clips). The stimuli for the attractive and unattractive conditions were fixed for all participants. For the stimuli presented in the control condition, we created mosaicked pictures and movie clips generated from stimuli presented in the other three experimental conditions.

Since our interest was in comparing neural responses across conditions, especially comparing the committed partner and the attractive opposite-sex individual, we sought to maximize the participants' reaction to the attractive female. To prepare the attractive

16 female's facial picture and movie clips, we recruited seven candidate females (aged 22-

1728 years) and took pictures of them with a neutral facial expression. For the stimuli signaling positive feedback as social approval, we recorded ten short movie clips for each in which a person expressed happiness with the face and performed positive gestures (e.g., smiling with the V-sign, OK-sign, or waving the right hand to the camera). For the nonapproval stimuli presented in error trials, we recorded a short clip where a person adopted a neutral facial expression without making any gestures. The models were asked to imitate the sample pictures and movie clips, during which they were photographed and recorded. The resulting pictures and movie clips were modified using Adobe Photoshop 
1 and Premiere Pro. Before the fMRI experiment, 20 male participants who did not

2 participate in the fMRI study rated the movie clips of the models' neutral and happy

3 expressions on a 7-point scale of facial attractiveness (1: very unattractive, 7: very

4 attractive). Using the means of these ratings, we selected the most attractive female and

5 the least attractive female. Two-way ANOVA with factors for the model (attractive or

6 unattractive) and expression (a movie clip with a neutral expression and mean ratings for

7 ten movie clips with happy expressions) confirmed significant main effects for model

8 (attractive $>$ unattractive: $\mathrm{F}(1,19)=96.06, \mathrm{p}<0.001, \eta_{\mathrm{p}}{ }^{2}=0.83$ ) and expression (happy

9 > neutral: $\left.\mathrm{F}(1,19)=7.87, \mathrm{p}=0.011, \eta_{\mathrm{p}}{ }^{2}=0.29\right)$ in the absence of an interaction effect

$10 \quad\left(\mathrm{~F}(1,19)=0.13, \mathrm{p}=0.72, \eta_{\mathrm{p}}^{2}=0.007\right)$. Thus, the stimuli for highly attractive and

11 unattractive females were prepared, for whom the clips with happy expressions were

12 considered preferable to those with a neutral expression. These stimuli were presented as

13 attractive and unattractive conditions in the SID task.

14 We also obtained pictures and movie clips of the female partners of the fMRI

15 participants using the same procedure described above. The females participated in the

16 recording without the presence of the fMRI participants. They were asked not to disclose

17 any details of the recording to their partners until the experiment was completed. 
1 2. Questionnaire measuring relationship commitment and attitudes toward 2 extrapair relationships

3 Following task completion, the participants completed two questionnaires on relationship 4 quality, including relationship commitment and attitudes toward extrapair relationships.

5 Since these features have been demonstrated to influence relationship duration (Simpson 6 1987; Betzig 1989; Felmlee et al. 1990; Miller 1997; Whisman et al. 1997; Amato and 7 Previti 2003; Le et al. 2010; Ueda et al. 2017), we expected that they could be associated 8 with neural representations related to the partner. The results of this exploratory analysis 9 are summarized in Sections 6 and 7 in the Supplemental Material.

To assess the degree of relationship commitment, we used a standardized questionnaire (Gagne and Lydon 2003). This questionnaire has nine items, of which four inquire into the extent to which the respondent feels committed to, obligated to, attached to, and a sense of duty toward the relationship (moral commitment factor). The next four items inquire into the extent to which the respondent enjoys the current relationship, feels enthusiastic about it, is not burdened by it, and would not feel relieved if it were to end (enthusiastic commitment factor). The participants responded to these items on a 9-point scale (1: not at all, 9: extremely). The last item asks respondents to estimate how long they expect their relationships to last on a scale of 1 (a week or so) to 9 (decades). Following the procedure given by Gagne and Lydon (2003), we excluded the duty and obligation scores when calculating the aggregated score, as they were not significantly correlated with the remaining items in the original study. Then, we created an aggregated relationship commitment score by averaging the scores of the remaining 7 items. Higher scores represent greater relationship commitment. The mean score across participants was $7.09(\mathrm{SD}=1.27$, range $=2.29-9.00)$. Interitem reliability was very high $($ Cronbach's $\alpha=$ 
$10.84)$ and comparable to that of the original study $(\alpha=0.87)$. Before conducting statistical

2 tests, we performed winsorization on one participant's relationship scores whose scores

3 (aggregated, moral, and enthusiastic commitment scores) were 3 SDs below the means

4 across all participants; that is, his scores were replaced with the next lowest scores. The

5 correlation coefficients of the aggregated relationship commitment score with the

6 subscales were 0.73 (with moral commitment score) and 0.94 (with enthusiastic

7 commitment score).

8 The questionnaire to assess tolerant attitudes toward extrapair relationships asked

9 participants to respond to the following three prompts on a 7-point scale: a) where is infidelity, from very negative or very positive; b) where is it, from very horrible to very

11 attractive; and c) where is it, from very impure to very pure? We confirmed that inter12 item reliability was sufficiently high $(\alpha=0.70)$, and the correlations of item scores with 13 total scores (not corrected for item overlap) were high for all items (item 1, r = 0.78; item

$142, r=0.82$; and item $3, r=0.78)$. An aggregated attitude score was created by averaging 15 the scores for the three items, where higher scores represented a greater tolerance for 16 extrapair relationships. The mean score across participants was $2.25(\mathrm{SD}=1.10$, range $=$ 17 1.00-4.67). This relatively low mean score confirms that the committed individuals who 18 participated in the current study generally demonstrated less tolerant attitudes toward extrapair relationships. 


\section{3. Region of interest definition}

2 We anatomically defined regions of interest (ROIs) for the left and right nucleus

3 accumbens (NAcc) based on the Individual Brain Atlas using Statistical Parametric

4 Mapping software (IBASPM; Aleman-Gomez et al. 2006), implemented with the WFU

5 PickAtlas (Wake Forest University, Winston-Salem, NC; Maldjian et al. 2003). The sizes

6 of the left and right NAcc mask images were 50 and 77 voxels, respectively. We also

7 investigated the medial orbitofrontal cortex (mOFC), a key region for subjective

8 evaluation of facial attractiveness or preference (O'Doherty et al. 2003; Kranz and Ishai

9 2006; Ishai 2007; Kim et al. 2007). A meta-analysis of the monetary incentive delay task indicated a functional dissociation between the NAcc and mOFC, suggesting greater mOFC responses during reward receipt relative to anticipation (Oldham et al. 2018). We constructed sphere mask images within the mOFC with center coordinates drawn from the automated meta-analysis of the NeuroSynth database (http://www.neurosynth.org; downloaded on 12 December 2019). First, we obtained statistical maps based on a metaanalysis of 470 studies associated with "value" (taken from a keyword search), and we set the center coordinates of the anatomically defined mOFC ROIs: the left mOFC centered on MNI coordinates $-6,40,-12, Z=7.52$; the right $\mathrm{mOFC}$ centered on MNI coordinates $6,40,-12, \mathrm{Z}=4.62$. Then, bilateral mOFC ROIs were defined as spheres with a 4-mm radius (33 voxels) centered on each coordinate using MarsBar software (Brett et al. 2002). The mask sizes were determined to be nearly equivalent to the bilateral NAcc ROI masks. We also created an ROI mask as a sphere with a 4-mm radius within the white matter (splenium of corpus callosum, centered on MNI coordinates $0,-30,20$ ). Supplemental Figure 1 illustrates these masks. 


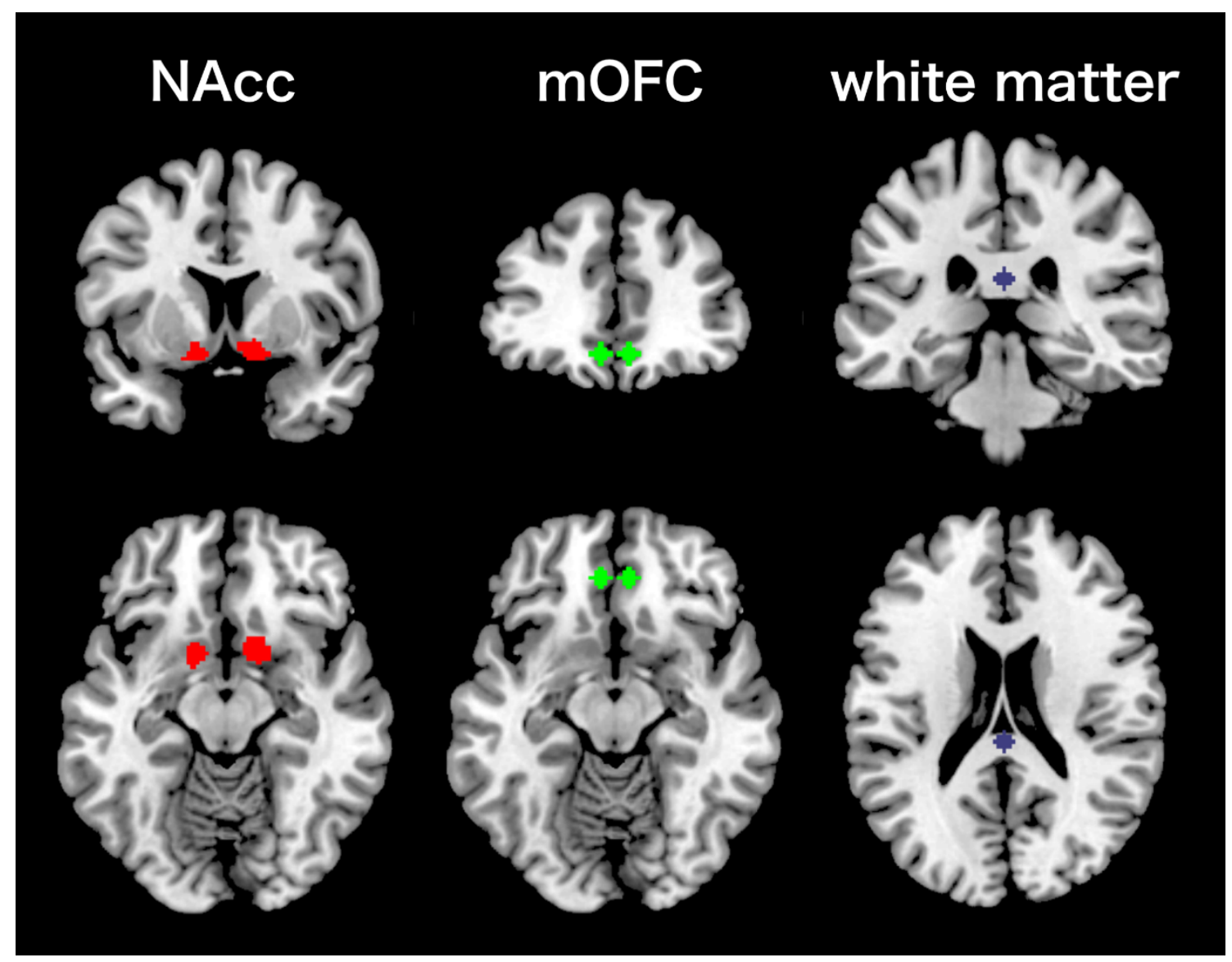

$1 \quad$ Supplemental Figure 1

2 The mask images for the regions of interest (ROIs) used in the classification analysis. We

3 anatomically defined the bilateral nucleus accumbens (NAcc) from the Individual Brain

4 Atlas using Statistical Parametric Mapping (IBASPM) software. We also generated

5 sphere mask images of the bilateral medial orbitofrontal cortex (mOFC: left centered on

6 MNI coordinates $-6,40,-12$; right centered on MNI coordinates $6,40,-12$ ) and of white

7 matter (splenium of corpus callosum: centered on MNI coordinates $0,-30,20$ ). 


\section{4. Positive reactions to the committed partner}

2 The greater preference for the happy expression of the partner compared with that of the

3 attractive female, which we observed in the rating task (see Figure 2), might represent a

4 positive illusion experienced by romantically involved individuals (Murray et al. 1996;

5 Murray and Holmes 1997; Barelds-Dijkstra and Barelds 2008; Barelds et al. 2011). We

6 anticipated that this greater preference for the movie clips of the partner females would

7 be observed only in the fMRI participants. To test this prediction, we recruited an

8 independent group of 20 heterosexual male participants who did not participate in the

9 fMRI study. They were asked to rate the facial attractiveness of images of faces with neutral expressions (1: very unattractive, 7 : very attractive) and the likeability of movie clips with happy expressions (1: not at all, 7: extremely) for all females presented in the SID task.

As expected, the results obtained in this independent group and the fMRI participants yielded a stark contrast. One-way ANOVA for the attractiveness ratings of the facial images revealed a significant effect of condition $(F(2,38)=32.21, p<0.001$, $\eta_{\mathrm{p}}{ }^{2}=0.63$ ), and post hoc t-tests with adjusted p-values with Bonferroni correction (i.e., adjusted $p$-value $=p$-value multiplied by 3 ) indicated significant differences across all conditions (partner vs. attractive: $\mathrm{t}(19)=4.43$, adjusted $\mathrm{p}<0.001, \mathrm{~d}=0.73,95 \%$ confidence interval $(\mathrm{CI})$ for the mean difference $=[0.59,1.65]$; partner vs. unattractive: $\mathrm{t}(19)=4.79$, adjusted $\mathrm{p}<0.001, \mathrm{~d}=0.85,95 \% \mathrm{CI}$ for the mean difference $=[0.50,1.27]$ attractive vs. unattractive: $\mathrm{t}(19)=6.69$, adjusted $\mathrm{p}<0.001, \mathrm{~d}=1.37,95 \% \mathrm{CI}$ for the mean difference $=[1.37,2.63])$. The participants in the independent group rated the image of the attractive female with a neutral expression as more attractive than images of nearly all partners (Supplemental Figure 2A). We found that only one of the 38 partners was 
1 assigned a mean attractiveness rating across participants that was higher than the mean

2 for the attractive model. These results indicated a successful manipulation of stimuli (i.e.,

3 the attractive model was considered more attractive than the majority of partner females)

4 and the positive illusion of the fMRI participants. As a further indication of this positive

5 illusion, the participants in the fMRI study exhibited greater preference for their partner's

6 movie clips than the participants in the independent group did $(\mathrm{t}(37)=13.24, \mathrm{p}<0.001$,

$7 \mathrm{~d}=2.10,95 \% \mathrm{CI}$ for the mean difference $=[1.51,2.06]$; Supplemental Figure 2B), and

8 no correlation between the likeability ratings for the two groups was observed for the

9 partner females $(\mathrm{r}=0.03, \mathrm{t}(36)=0.16, \mathrm{p}=0.87,95 \%$ CI for the coefficient $=[-0.30$,

10 0.34]; Supplemental Figure 2C). 

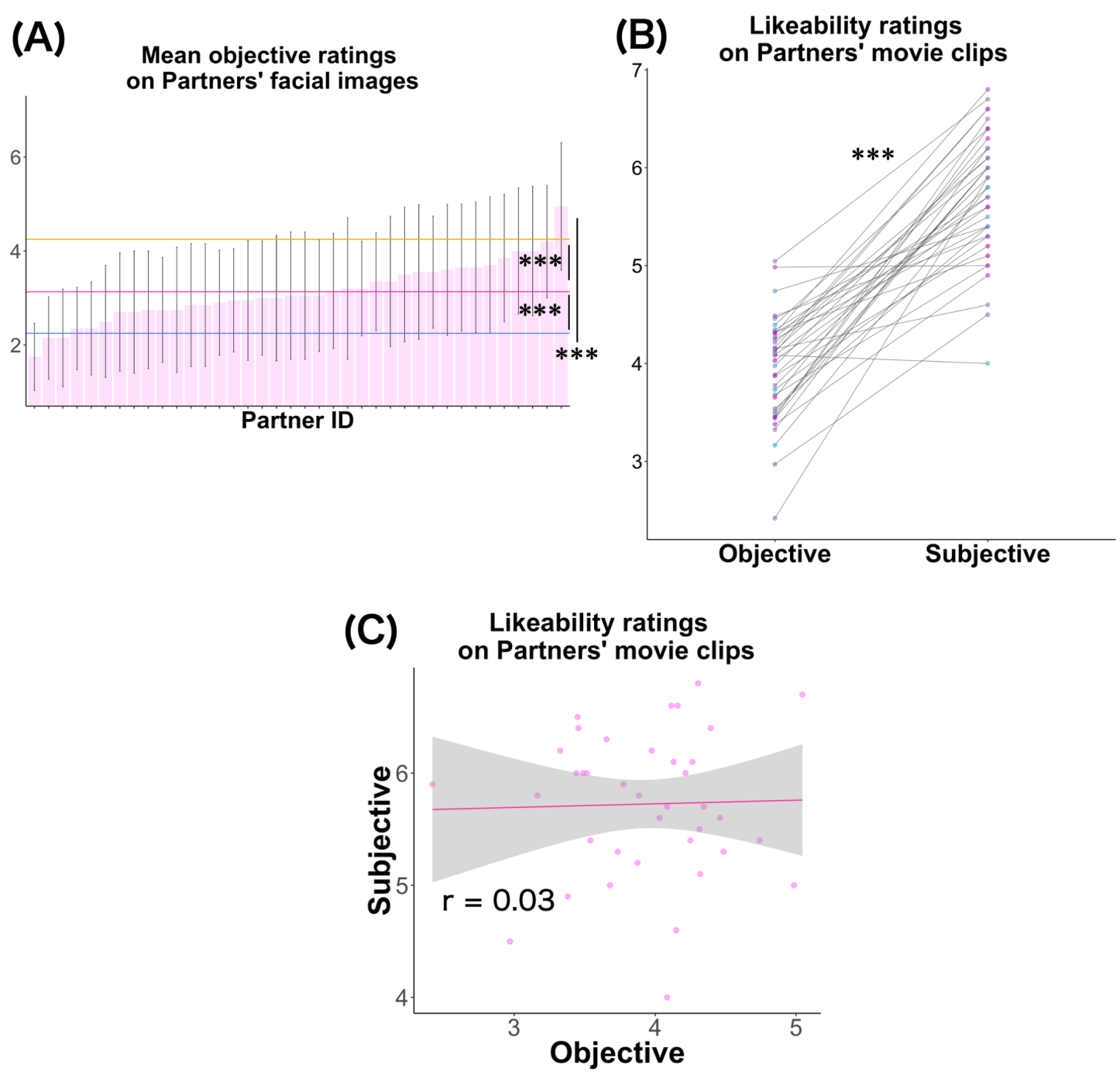

$2 \quad$ Supplemental Figure 2

3 Comparison of ratings given by the fMRI participants (termed subjective) and the

4 independent group (termed objective). (A) The mean attractiveness ratings for the

5 neutral-expression facial images of the 38 partner females across participants in the

6 independent group. The orange-colored horizontal line indicates across-participant mean

7 ratings for the attractive model $($ mean $=4.25, \mathrm{SD}=1.59)$. The pink line presents the mean

8 ratings for the partner females $($ mean $=3.13, \mathrm{SD}=0.98)$. The blue line indicates the mean

9 ratings for the unattractive model $($ mean $=2.25, \mathrm{SD}=1.02)$. The error bars indicate the 
1 standard deviation across participants. (B) The likeability of partners' happy-expression

2 movie clips rated by each group. Each dot represents the mean rating for the partner

3 female across participants in the group. (C) The scatter plot for likeability ratings on

4 partners' happy-expression movie clips between the two groups. Each dot represents the

5 mean rating for the given partner across participants, and the line with shaded areas

6 represents the results of the regression analysis and the $95 \%$ confidence interval. The

7 subjective score is the mean rating for the ten movie clips obtained from the fMRI

8 participants (male partner). The objective score was calculated from the mean rating for

9 ten movie clips obtained from the independent group participants. ${ }^{* * *} \mathrm{p}<0.001$ 


\section{5. Classification between anticipation of social and nonsocial stimuli}

2 The SID task in the present study included a control condition in which a mosaicked

3 picture was presented as a cue, and in the outcome phase, a mosaicked movie clip 4 appeared on the screen, regardless of the performance. To determine whether NAcc

5 activity could discriminate the control condition from the other experimental conditions,

6 we performed a pairwise classification analysis between the social (partner, attractive,

7 and unattractive) and nonsocial (control) conditions during the anticipatory delay phase.

8 This classification, however, involves an imbalance issue. That is, while the partner,

9 attractive, and unattractive conditions are labeled social conditions, only the control

10 condition is labeled a nonsocial condition; therefore, the numbers of trials for each label

11 are not equalized, which could bias the classification accuracies. To solve this issue, we

12 performed a bootstrap sampling procedure; that is, we randomly removed some samples

13 (without replacement) to ensure that the number of samples in each label was equalized

14 for each run. This process was repeated 1,000 times, which resulted in average

15 classification accuracy for each participant. We observed that mean social vs. nonsocial

16 classification accuracy across participants was above chance (one-sample t-test compared

17 with $50 \%$; mean $=54.0 \%, \mathrm{SD}=9.1 \%, \mathrm{t}(37)=2.69, \mathrm{p}=0.005, \mathrm{~d}=0.43,95 \% \mathrm{CI}$ for the

18 mean $=[51.5 \%, \infty]$, one-tailed), supporting the notion that the anticipation of positive

19 feedback from the cued person is encoded in the NAcc in a distinguishable way from that of nonsocial stimuli. 
1 6. Exploratory correlation analyses between classification accuracy in the NAcc and

\section{2 relationship commitment}

3 We explored whether individual differences in relationship commitment were associated with classification accuracy in the NAcc. However, the present study's sample size is rather small to provide adequate power for the across-participant correlation tests. To achieve a power of 0.9 to detect the medium-size effect, a sample size of 112 is required (Correlation: Bivariate normal model on a G-Power Version 3.1.9.4; Faul et al. 2007, 2009). Thus, we note that our correlation analyses only provide preliminary results. (i.e., mean of the left and right regions) in the NAcc in the anticipatory delay phase, which is based on the assumption that higher classification accuracy represents better encoding of stimulus information (Etzel et al. 2016). To control the familywise error rate of multiple comparisons (i.e., classifications between partner vs. attractive, partner vs. unattractive, and attractive vs. unattractive), we report adjusted p-values with Bonferroni correction (i.e., adjusted $p$-value $=p$-value multiplied by 3 ). We observed that individuals with greater commitment exhibited significantly higher classification accuracy (i.e., more distinguishable activation patterns) between the partner and unattractive conditions in the NAcc $(r=0.47, t(36)=3.17$, adjusted $p=0.009,95 \% C I$ for the coefficient $=[0.17,0.68]$; Supplemental Figure 3). This effect remained significant even after controlling for the participant's age and log-transformed length of the relationship with the current partner (standardized regression coefficient $\beta=0.41, \mathrm{t}(34)=2.30, \mathrm{p}=0.028,95 \% \mathrm{CI}$ for the coefficient $=[0.05,0.76])$. However, we found no significant correlation with relationship commitment when using the classification accuracy between the partner and attractive condition $(r=0.19, \mathrm{t}(36)=1.13$, adjusted $\mathrm{p}=0.79,95 \% \mathrm{CI}$ for the coefficient $=[-0.14$, 
$10.48])$ or between the attractive and unattractive condition $(\mathrm{r}=-0.04, \mathrm{t}(36)=-0.23$,

2 adjusted $\mathrm{p}=1.00,95 \% \mathrm{CI}$ for the coefficient $=[-0.35,0.28])$, as illustrated in

3 Supplemental Figure 3.

As described in Section 2, the relationship commitment scale that we used (Gagne and Lydon 2003) consisted of two factors, moral commitment and enthusiastic

6 commitment. We observed similar correlations between these subscale scores and

7 classification accuracy between the partner and unattractive conditions (moral

8 commitment score: $\mathrm{r}=0.39, \mathrm{t}(36)=2.52$, adjusted $\mathrm{p}=0.049,95 \% \mathrm{CI}$ for the coefficient

$9=[0.08,0.63]$; enthusiastic commitment score: $\mathrm{r}=0.53, \mathrm{t}(36)=3.79$, adjusted $\mathrm{p}=0.002$, $95 \% \mathrm{CI}$ for the coefficient $=[0.26,0.73])$. No significant correlations were found between

11 the subscale scores and the classification accuracy between the partner and attractive 12 condition (moral commitment score: $\mathrm{r}=0.10, \mathrm{t}(36)=0.59$, adjusted $\mathrm{p}=1.00,95 \% \mathrm{CI}$ for

13 the coefficient $=[-0.23,0.41]$; enthusiastic commitment score: $r=0.23, t(36)=1.43$,

14 adjusted $p=0.48,95 \% \mathrm{CI}$ for the coefficient $=[-0.10,0.51])$ or between the attractive

15 and unattractive condition (moral commitment score: $\mathrm{r}=-0.01, \mathrm{t}(36)=-0.07$, adjusted $\mathrm{p}$

$16=1.00,95 \% \mathrm{CI}$ for the coefficient $=[-0.33,0.31]$; enthusiastic commitment score: $\mathrm{r}=$ $17-0.10, \mathrm{t}(36)=-0.62$, adjusted $\mathrm{p}=1.00,95 \% \mathrm{CI}$ for the coefficient $=[-0.41,0.22])$. 


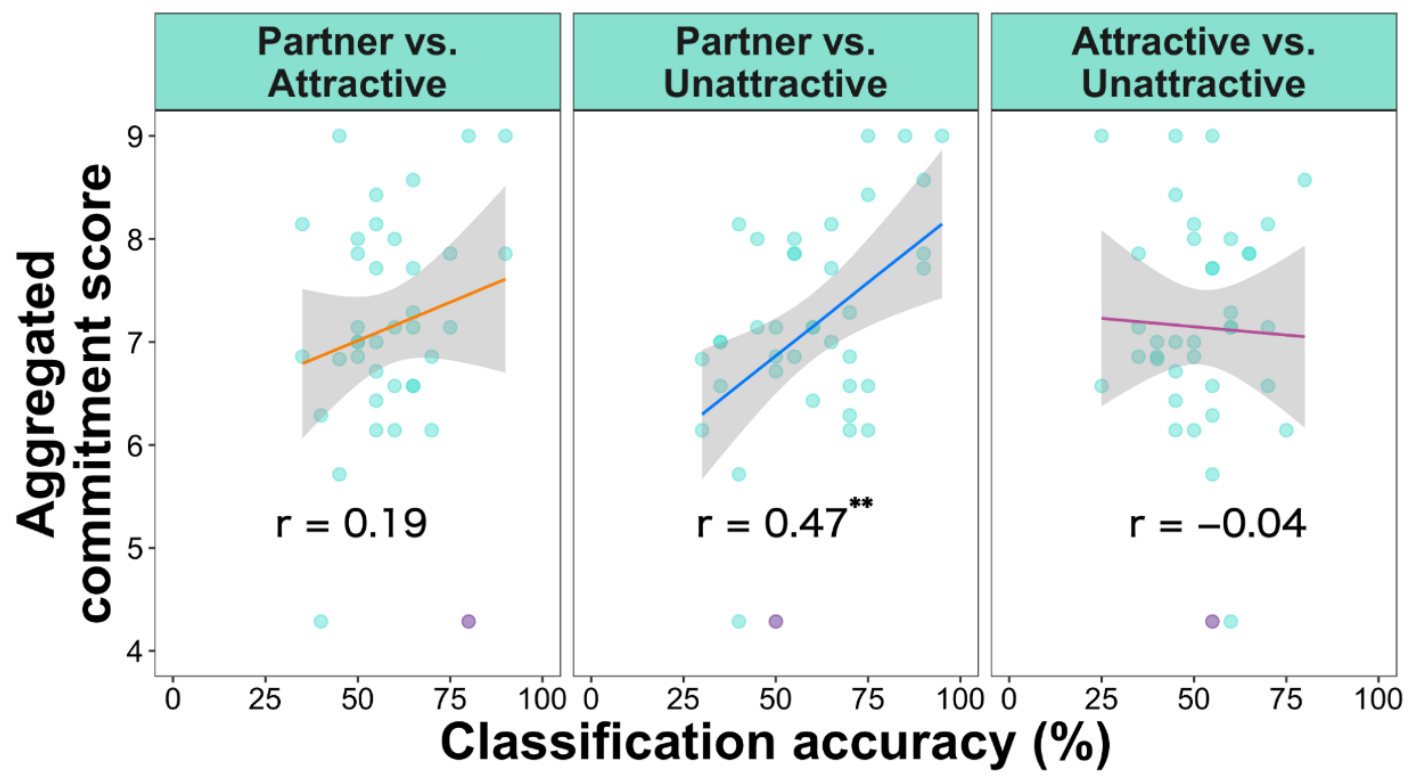

$3 \quad$ Supplemental Figure 3

4 Scatter plots for the relationships between classification accuracy for the NAcc activity

5 patterns during the anticipatory delay phase and relationship commitment across

6 participants. Each dot denotes a participant, and the lines with shaded areas represent the

7 results of the regression analysis and the $95 \%$ confidence intervals. The purple dots

8 denote one participant whose commitment scores were winsorized. ${ }^{* *} \mathrm{p}<0.01$ 
1 7. Exploratory correlation analyses between neural activity patterns in the NAcc

\section{2 and attitudes toward extrapair relationships}

3 We explored whether neural activity patterns in the NAcc during the anticipatory delay

4 phase were associated with attitudes toward extrapair relationships assessed by a

5 questionnaire. As illustrated in Supplemental Figure 4, no significant correlations were

6 observed in all conditions (partner vs. attractive: $\mathrm{r}=-0.26, \mathrm{t}(36)=-1.61$, adjusted $\mathrm{p}=$

$7 \quad 0.35,95 \%$ CI for the coefficient $=[-0.53,0.07]$; partner vs. unattractive: $r=-0.18, \mathrm{t}(36)$

$8=-1.09$, adjusted $\mathrm{p}=0.85,95 \% \mathrm{CI}$ for the coefficient $=[-0.47,0.15]$; attractive vs.

9 unattractive: $r=-0.12, t(36)=-0.74$, adjusted $p=1.00,95 \%$ CI for the coefficient $=$ $10 \quad[-0.43,0.21] ;$ p-values were adjusted by multiplying 3$)$.

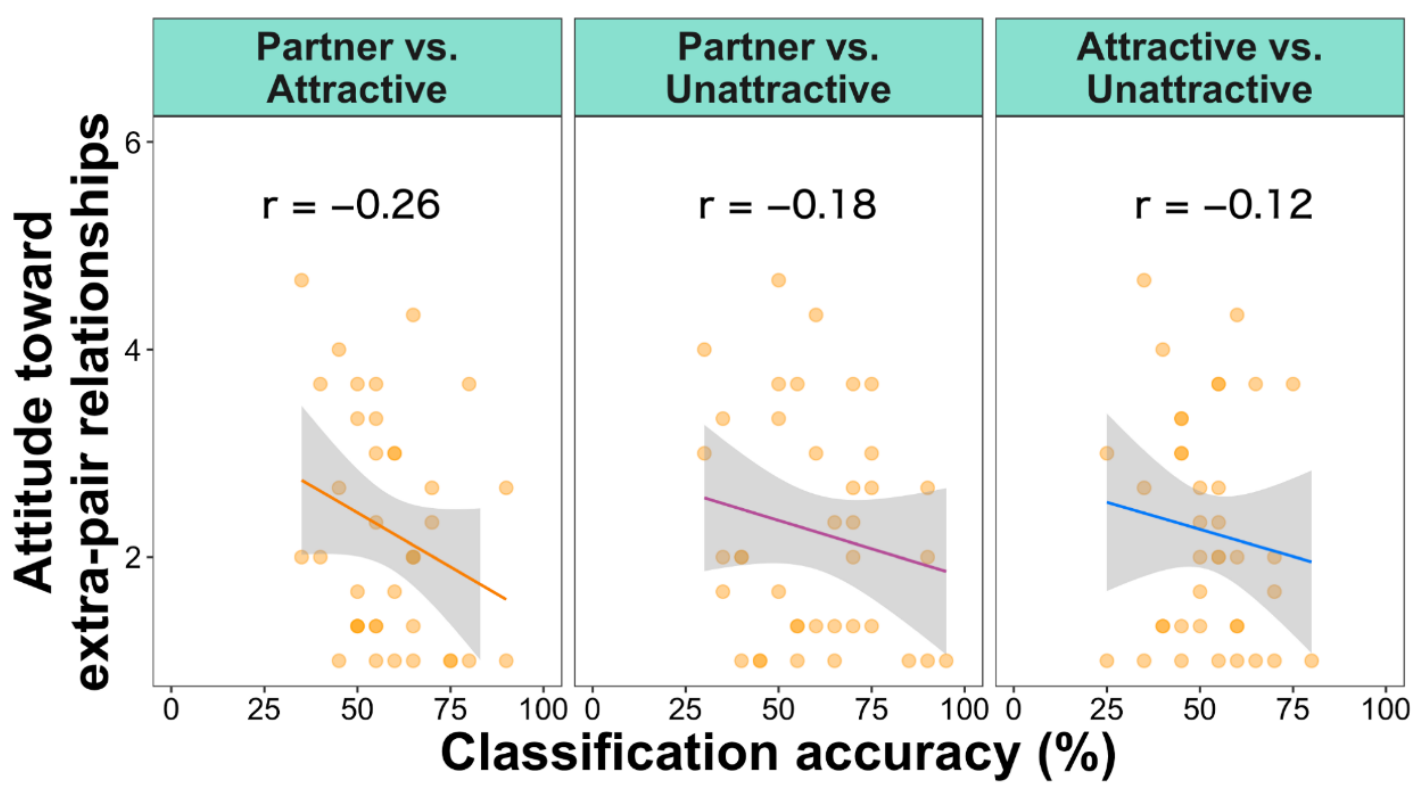

$12 \quad$ Supplemental Figure 4

13 Scatter plots for the relationships between the classification accuracy of the NAcc during

14 the anticipatory delay phase and attitudes toward extrapair relationships. Each dot denotes

15 a participant, and the lines with shaded areas represent the results of the regression 
1 analysis and the $95 \%$ confidence intervals. 
1 8. Classification between obtaining positive feedback from social and nonsocial

2 stimuli

3 To determine whether mOFC activity could discriminate the control condition from the

4 other experimental conditions, we performed a pairwise classification analysis between

5 the social (partner, attractive, and unattractive) and nonsocial (control) conditions during

6 the outcome phase. We used a bootstrap sampling procedure (see Section 5) and observed

7 above-chance classification accuracy, similar to the finding in the NAcc during the

8 anticipatory delay phase (one-sample t-test compared with $50 \%$; mean $=61.9 \%$, SD $=$

$9 \quad 11.7 \%, \mathrm{t}(37)=6.22, \mathrm{p}<0.001, \mathrm{~d}=0.99,95 \% \mathrm{CI}$ for the mean $=[58.6 \%, \infty]$, one-tailed). 


\section{9. Supplemental Discussion}

2 Here, we present some future directions in this line of research. First, sex differences are

3 important topics to be pursued. Because we limited our study to only heterosexual male

4 volunteers to avoid possible confounding effects, our results do not indicate whether

5 similar neural mechanisms would be observed in females or homosexual individuals.

6 Males have been reported to express a desire for romantic relationships with more

7 potential partners than females (Buss and Schmitt 1993; Wiederman 1997). Additionally,

8 the probability of extramarital sex experiences is believed to be higher in males than in

9 females (e.g., Atkins et al. 2001). In addition to relationship maintenance, other studies have focused on sex differences in behaviors of mate switching, which potentially reflects that the cost of mate switching is likely to be higher in females (e.g., damage to reputational components of her mate value or loss of support from her partner; Buss et al. 2017). According to the theoretical framework that these sex differences may be deeply related to different strategies for mate selection (Buss 1989; Buss and Schmitt 1993), females can be expected to exhibit a more significant difference in decoding accuracy relative to their long-term partner or alternative partners than males, which might represent a greater motivation to maintain a committed relationship.

Second, longitudinal assessment could provide further insight into how dissociable neural representations of the long-term partner and other opposite-sex individuals are formed. It is well known that relationship quality dynamically changes over time. The early stages of a romantic relationship usually involve limerence, the involuntary romantic infatuation with the partner (Tennov 1979; Fisher et al. 2016; Ueda et al. 2018), which is believed to be sustained by the limbic reward system (Aron et al. 2005). However, this sort of addictive passionate love generally loses intensity over time 
1 (Traupmann and Hatfield 1981; Sternberg 1986; Tucker and Aron 1993). Several studies

2 have found neurochemical changes associated with relationship quality (Marazziti et al.

3 1999; Marazziti and Canale 2004). We, therefore, expect to find linear or nonlinear

4 temporal changes in neural representations related to the partner over time. In support of

5 this hypothesis, one study that surveyed relationship quality in marital relationships

6 reported a U-shaped association between happiness and relationship duration,

7 characterized by the highest happiness in the earliest and latest years of marriage

8 (VanLaningham et al. 2001).

9 Third, investigations of cultural differences would also be valuable. It has been reported that $84 \%$ of the 853 societies tabulated in Murdock's Ethnographic Atlas permit polygyny, and $44 \%$ of those cultures regard polygyny as the preferred marriage form (Van den Berghe 1979). Attitudes toward single-minded romantic relationships might be different in those societies and would be expected to involve different neural mechanisms.

14 Furthermore, some researchers have hypothesized that attitudes about romantic 15 relationships can alter over time, which could be modulated by social factors such as 16 social norms and exposure to media (Buss et al. 2001; Hatfield et al. 2010). For instance, 17 initiating a romantic relationship from online dating has recently been prevalent in the

18 United States (Rosenfeld et al. 2019), which may have influenced our attitude toward romantic relationships. 
1

2

\section{References}

Aleman-Gomez, Y., Melie-Garcia, L., \& Valdes-Hernandez, P. (2006). IBASPM: Toolbox for automatic parcellation of brain structures. Presented at the 12th Annual Meeting of the Organization for Human Brain Mapping, June 11-15, 2006, Florence, Italy. Available on CD-Rom in Neuroimage, Vol 27, No 1.

Amato, P.R., \& Previti, D. (2003). People's reasons for divorcing: Gender, social class, the life course, and adjustment. J Fam Issues 24:602-626.

Atkins, D.C., Baucom, D.H., \& Jacobson, N.S. (2001). Understanding infidelity: Correlates in a national random sample. J Fam Psychol 15:735-749.

Aron, A., Fisher, H., Mashek, D.J., Strong, G., Li, H., \& Brown, L.L. (2005). Reward, motivation, and emotion systems associated with early-stage intense romantic love. J Neurophysiol 94:327-337.

Barelds, D.P.H., Dijkstra, P., Koudenburg, N., \& Swami, V. (2011). An assessment of positive illusions of the physical attractiveness of romantic partners. J Soc Pers Relat 28:706-719.

Barelds-Dijkstra, P., \& Barelds, D.P.H. (2008). Positive illusions about one's partner's physical attractiveness. Body Image 5:99-108.

Betzig, L. (1989). Causes of conjugal dissolution: A cross-cultural study. Curr Anthropol 30:654-676.

Brett, M., Anton, J.L., Valabregue, R., \& Poline, J.B. (2002). Region of interest analysis using an SPM toolbox [abstract]. Presented at the 8th International Conference on Functional Mapping of the Human Brain, June 2-6, Sendai, Japan. Available on CD-Rom in Neuroimage, Vol 16, No 2.

Buss, D.M. (1989). Sex differences in human mate preferences: Evolutionary hypotheses 
tested in 37 cultures. Behav Brain Sci 12:1-49.

Buss, D.M., \& Schmitt, D.P. (1993). Sexual strategies theory: An evolutionary perspective on human mating. Psychol Rev 100:204-232.

Buss, D.M., Shackelford, T.K., Kirkpatrick, L.A., \& Larsen, R.J. (2001). A half century of mate preferences: The cultural evolution of values. J Marriage Fam 63:491-503.

Buss, D.M., Goetz, C., Duntley, J.D., Asao, K., \& Conroy-Beam, D. (2017). The mate switching hypothesis. Pers Individ Dif 104:143-149.

Etzel, J.A., Cole, M.W., Zacks, J.M., Kay, K.N., \& Braver, T.S. (2016). Reward motivation enhances task coding in frontoparietal cortex. Cereb Cortex 26:16471659.

Faul, F., Erdfelder, E., Lang, A.G., \& Buchner, A. (2007). G*Power 3: A flexible statistical power analysis program for the social, behavioral, and biomedical sciences. Behav Res Methods 39:175-191.

Faul, F., Erdfelder, E., Buchner, A., \& Lang, A.G. (2009). Statistical power analyses using G*Power 3.1: Tests for correlation and regression analyses. Behav Res Methods 41:1149-1160.

Felmlee, D., Sprecher, S., \& Bassin, E. (1990). The dissolution of intimate relationships: A hazard model. Soc Psychol Quart 53:13-30.

Fisher, H.E., Xu, X., Aron, A., \& Brown, L.L. (2016). Intense, passionate, romantic love: A natural addiction? How the fields that investigate romance and substance abuse can inform each other. Front Psychol 7:687.

Gagne, F.M., \& Lydon, J.E. (2003). Identification and the commitment shift: Accounting for gender differences in relationship illusions. Pers Soc Psychol B 29:907-919.

Hatfield, E., Rapson, R.L., \& Martel, L.D. (2010). Passionate love and sexual desire. In: 
Handbook of Cultural Psychology (Kitayama S, Cohen D, eds), pp 760-779. New York: Guilford Press.

Ishai, A. (2007). Sex, beauty and the orbitofrontal cortex. Int J Psychophysiol 63:181-185.

Kim, H., Adolphs, R., O'Doherty, J.P., \& Shimojo, S. (2007). Temporal isolation of neural processes underlying face preference decisions. Proc Natl Acad Sci U S A 104:18253-18258.

Kohls, G., Perino, M.T., Taylor, J.M., Madva, E.N., Cayless, S.J., Troiani, V., Price, E., Faja, S., Herrington, J.D., \& Schultz, R.T. (2013). The nucleus accumbens is involved in both the pursuit of social reward and the avoidance of social punishment. Neuropsychologia 51:2062-2069.

Kranz, F., \& Ishai, A. (2006). Face perception is modulated by sexual preference. Curr Biol 16:63-68.

Le, B., Dove, N.L., Agnew, C.R., Korn, M.S., \& Mutso, A.A. (2010). Predicting nonmarital romantic relationship dissolution: A meta-analytic synthesis. Pers Relationship 17:377-390.

Marazziti, D., \& Canale, D. (2004). Hormonal changes when falling in love. Psychoneuroendocrino 29:931-936.

Marazziti, D., Akiskal, H.S., Rossi, A., \& Cassano, G.B. (1999). Alteration of the platelet serotonin transporter in romantic love. Psychol Med 29:741-745.

Maldjian, J.A., Laurienti, P.J., Kraft, R.A, \& Burdette, J.H. (2003). An automated method for neuroanatomic and cytoarchitectonic atlas-based interrogation of fMRI data sets. Neuroimage 19:1233-1239.

Miller, R.S. (1997). Inattentive and contented: Relationship commitment and attention to alternatives. J Pers Soc Psychol 73:758-766. 
1 Murray, S.L., \& Holmes, J.G. (1997). A leap of faith? Positive illusions in romantic relationships. Pers Soc Psychol B 23:586-604.

Murray, S.L., Holmes, J.G., \& Griffin, D.W. (1996). The benefits of positive illusions: Idealization and the construction of satisfaction in close relationships. J Pers Soc Psychol 70:79-98.

O'Doherty, J., Winston, J., Critchley, H., Perrett, D., Burt, D.M., \& Dolan, R.J. (2003). Beauty in a smile: The role of medial orbitofrontal cortex in facial attractiveness. Neuropsychologia 41:147-155.

Oldham, S., Murawski, C., Fornito, A., Youssef, G., Yucel, M., Lorenzetti, V. (2018). The anticipation and outcome phases of reward and loss processing: A neuroimaging meta-analysis of the monetary incentive delay task. Hum Brain Mapp 39:33983418.

Rosenfeld, M.J., Thomas, R.J., \& Hausen, S. (2019). Disintermediating your friends: How online dating in the United States displaces other ways of meeting. Proc Natl Acad Sci U S A 116:17753-17758.

Simpson J.A. (1987). The dissolution of romantic relationships: Factors involved in relationship stability and emotional distress. J Pers Soc Psychol 53:683-692.

Sternberg, R.J. (1986). A triangular theory of love. Psychol Rev 93:119-135.

Tennov, D. (1979). Love and limerence: The experience of being in love. New York: Scarborough House.

Traupmann, J., \& Hatfield, E. (1981). Love and its effect on mental and physical health. In: Aging: Stability and change in the family (Fogel R, Hatfield E, Kiesler S, Shanas E, eds), pp 253-274. New York: Academic Press.

Tucker, P., \& Aron, A. (1993). Passionate love and marital satisfaction at key transition 
points in the family life cycle. J Soc Clin Psychol 12:135-147.

2 Ueda, R., Yanagisawa, K., Ashida, H., \& Abe, N. (2017). Implicit attitudes and executive control interact to regulate interest in extra-pair relationships. Cogn Affect Behav Neurosci 17:1210-1220.

5 Ueda, R., Yanagisawa, K., Ashida, H., \& Abe, N. (2018). Exective control and faithfulness: Only long-term romantic relationships require prefrontal control. Exp Brain Res 236:821-828.

8 Van Den Berghe, P.L. (1979). Human family systems: An evolutionary view. New York: Elsevier Press.

VanLaningham, J., Johnson, D.R., \& Amato, P. (2001). Marital happiness, marital duration, and the U-shaped curve: Evidence from a five-wave panel study. Social Forces 79:1313-1341.

Whisman, M.A., Dixon, A.E., \& Johnson, B. (1997). Therapist's perspectives of couple problems and treatment issues in couple therapy. J Fam Psychol 11:361-366.

Wiederman, M.W. (1997). Extramarital sex: Prevalence and correlates in a national survey. J Sex Res 34:167-174. 